\title{
EL ATLAS LINGÜÍSTICO Y ETNOGRÁFICO DE LA PROVINCIA DE SANTANDER (ESPANAA)
}

\author{
A don Ignacio Aguilera
}

\section{Preliminares}

La que he llamado tercera etapa de la geografía lingüistica ${ }^{1}$ se caracteriza por la aparición de los atlas de pequeños dominios, frente a los que, tradicionalmente, abarcaban territorios mucho más espaciosos. Para Jaberg, eran tales los atlas de Cataluña, de Córcega, del Lionesado, de Gascuña o de Flandes, frente a los de Francia, Italia, Rumania o Alemania ${ }^{2}$. Afirmación que es cierta en cuanto a su planteamiento general, no en cuanto a su realización. Evidentemente, no se motivaron igual las pesquisas de Cataluña y las de Córcega, que las del Lionesado o Gascuña; tampoco me parece mejor decir, como hace el gran maestro suizo, que son preferibles las designaciones de nacional y regional, por cuanto pueden confundir dos hechos heterogéneos: el político y el lingüístico. Cataluña es una región dentro de una ordenación estatal, pero el catalán es, lingüisticamente, una estructura independiente, como el francés, el español o el italiano, aunque como en el caso de todos ellos, los territorios en que se habla no constituyen una sola entidad administrativa: Cataluña, Valencia y Baleares son parte integrante de España; los Pirineos Orientales, de Francia; Alguer, de Italia. Pero lo que me interesa en este momento es señalar que Jaberg ya habló de que Bruneau, Bloch y Millardet $^{3}$ en sus trabajos sobre

1 Vid., por ejemplo, Los Atlas Lingüisticos de España ("Presente y futuro de la lengua española", t. I, Madrid, 1963, p. 426).

2 Grossräumige und kleineräumige Sprachatlanten ("Vox Romanica", XIV, I954, p. 3).

- Chardes BRUneau, Enquete linguistique sur les patois d'Ardenne. Paris, 1913; OsCAR BLOCH, Atlas Linguistique des Vosgues méridionales. Parts, I917; GEORges MiLl,ardet, Petit Atlas linguistique d'une région des Landes, contribution a la dialectologie gasconne. Toulouse-Paris, I910. 
ámbitos más restringidos, hicieron una cartografía de minimos dominios ${ }^{1}$. Así, pues, el proyecto que trato de presentar tiene un puesto muy claro dentro de la lingüística románica por cuanto es un atlas de un pequeño dominio, pero, si regiones como Andalucía tienen una superficie mayor que muchos estados nacionales, no es menos cierto que el Atlas de Santander será, más que nada, lo que Jaberg llamó un atlas minimo.

Inmediatamente surge la pregunta: ¿merece la pena un trabajo de esta índole? Porque, en efecto, la geografía lingüística tiene uno de sus fundamentos en abarcar superficies territoriales que, por su extensión, permitan la diferenciación espacial de la lengua. Si esto no ocurre, los fines pretendidos difícilmente se podrán alcanzar, pues la falta de contraste convertirá en manchas homogéneas aquellas superficies objeto de nuestro estudio. $\mathrm{Y}$ si no, piénsese en atlas muy pequeños como el de Maramureş ${ }^{2}$, el del Macizo Central ${ }^{3}$ o, para no salir de España, el de Andorra o el del Valle de Arán ${ }^{4}$. Nada de extraño tiene, según he dicho alguna vez, que Andorra manifieste para los lingüistas un interés mucho mayor si se considera el único punto con que figuró en el Atlas Linguiistic de Catalunya, que no en los seis del Atlas Lingüistic de Andorra ${ }^{5}$.

Si volviéramos al trabajo de Jaberg, al que he tenido que referirme podriamos encontrar en él una definición que puede valernos como punto de partida: en el atlas regional se debe ver un dominio lingüístico de relativa homogeneidad y diferenciado de los otros dialectos próximos por unas características propias ${ }^{6}$. Esto es, resulta imprescindible conocer varias estructuras dialectales para que la que estudiamos se pueda personificar con claridad. O dicho de otro modo, la geografía lingiiística no depende tanto de la superficie cuanto de la diversidad. Una provincia podrá ser muy uniforme y, por tanto, inútil para una geografía lingüistica exenta, o podrá ser muy heterogénea, en cuyo caso el microcosmos podrá valer para estudios en todo comparables

1 JABIRG, art. cit., p. 3.

2 Vid. K. JABERG, Der rumänische Sprachatlas und die Struktur des dacorumämischen Sprachgebietes ("Vox Romanica", V, I940, p. 22). La situación que describo en el texto procede del Atlasul Linguistic Roman pe regioni. Maramures, t. I, 1969; t. II, I97I.

3 PIERRE NAUTON, Atlas linguistique et etnographique du Massif Central. Paris, 1957-6I (3 vols.).

- ANTon GrIERA, Atlas lingüistic de Andorra. Barcelona, r96o; del mismo autor, Atlas lingüistic de la Vall d'Avan. Barcelona, r973.

- Ios Atlas lingǘsticos de España, ya citados, pp. 417-4I8.

- Grossräumige, p. 7 . 
a los que hacemos con macroestructuras ${ }^{1}$. Grande, pequeño, mínimo, son adjetivos cuantitativos, no cualitativos. Lo que pretendo con estas páginas es responder a la pregunta formulada anteriormente: ¿merece la pena un trabajo de esta índole? Y mi respuesta será afirmativa si podemos disponer de elementos de comparación y contraste. Es lo que voy a considerar ${ }^{2}$.

\section{Unas muestras de fonética y morfología}

No merece la pena discutir aquí si conviene más un atlas nacional o multitud de atlas regionales. Son tan diversas las particularidades de cada uno de ellos, que los hacen totalmente heterogéneos: un atlas nacional vale para unas cosas y un atlas regional, para otras; ni se excluyen, ni se neutralizan. Los caracteres de los atlas de pequeños dominios son los que mil veces se han dicho: densidad de encuestas, y, por consiguiente, mejor conocimiento de las diversidades; precisión en los datos allegados, $\mathrm{y}$, por tanto, superación de ciertas deficiencias de los atlas grandes; captar con ellos realidades culturales mucho mejor que si deslizáramos rápidamente la vista por un vasto territorio. Todo ello, es lógico, pretende adentrarse, y agotar si es posible de un modo exhaustivo, en la peculiaridad regional, lo que no puede hacer un atlas general ${ }^{3}$. Evidentemente, son realidades muy distintas: no es cantidad

1 Una visión sobre los atlas peninsulares se puede encontrar en mi ponencia Estado actual de los atlas lingütsticos españoles ("Actas del XII Congreso Internacional de Lingüística y Filologia Románicas», t. I, Madrid, 1968, pp. I5 I-I 74). Esas páginas pueden ser útiles - a pesar de su necesario envejecimiento - por los problemas metodológicos que suscitan.

2 El problema de la prioridad de los atlas regionales o los nacionales me ha ocupado en alguna ocasión. Es exactamente la observación de V. Rusu al trabajo de Paiva Boléo que cito seguidamente, pero una cosa es la teoria y otra las posibilidades prácticas de la realización. Por otra parte, el trabajo del investigador portugués compara hechos diversos: el $I L B$ es un proyecto limitado a una estructura singular (el portugués), mientras que el $A L P I$ afecta a una macroestructura compleja (tres lenguas románicas y sus muchos dialectos), cf. Le matérial de l'I.L.B. et quelques études de comparaison avec l'A.L.P.I. et l'Atlas previo dos falares baianos ("Actes du XIII' Congrès International de Linguistique et Philologie Romanesn, II, I976, pp. 201-221. La intervención de Rusu, en la p. 222). El trabajo se reimprimió con importantes adiciones en la "Revista Portuguesa de Filologín, XVII, 1975-76, pp. 339-385; la separata tiene, además, unos indices muy útiles.

3 Cf. Los Atlas Lingüisticos de España, ya citados, pp. 421-425. 


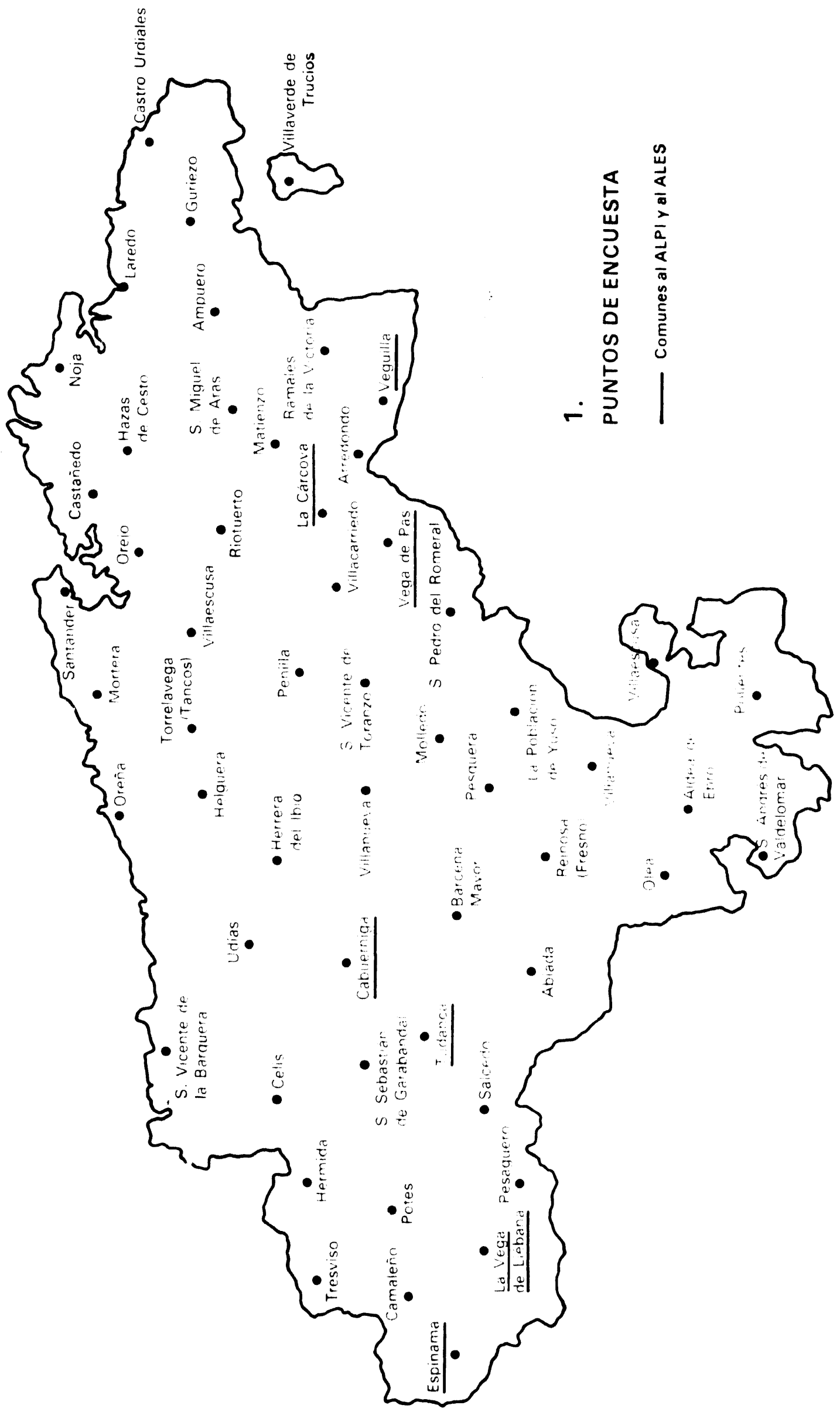


de información lo que buscamos, sino, además, cualidad. $\mathrm{Y}$ en este sentido el atlas de Santander nos podrá servir como piedra de toque para muchas cuestiones generales.

Porque la empresa cartográfica que presento es, en sí misma, muy compleja, y ello aleja de nosotros la duda de su validez. Tomemos un par de referencias. En 1936, Espinosa y Rodriguez Castellano estudiaron La aspiración de la "hi" en el Sur y Oeste de España ${ }^{1}$, pero sus observaciones, como era de esperar, no alcanzaron a nuestra provincia; mucho después, en 1954, el segundo de estos investigadores dio a conocer el Estado actual de la "his aspirada en la provincia de Santander ${ }^{2}$, pormenorizada monografía hecha con todo rigor. En ella se pueden descubrir tres ámbitos distintos: uno, de jota castellana, que ocuparfa centro, oriente y sur de la provincia; otro, de aspiración, cuyos límites serían los lados de un rectángulo con vértices orientales en Lloredo, Bárcena y, en línea recta, Dobres-Espinama hasta perderse en Asturias, donde podríamos situar el cuarto vértice; por último, una tercera región - hoy rota - en la cual hay restos de las aspiración antigua en unos sonidos intermedios ${ }_{x}^{k}, h^{x}$, que aún viven de Lloredo al Miera y de Santander a Villaescusa, y en la cuenca del Luena (restos en Entrambasmestas y San Miguel de Luena). Esta monografía es - lo he dichoexcelente, pero, así y todo, no podemos pedirle sino aquello que ofrece. El atlas de la provincia permite mayores precisiones en los puntos donde se realizó encuesta $y$, sobre todo, analizar la aspiración en ejemplos cuyo étimo no remonte a $F$ - latina, tal el caso del castellano [x] o de las aspiraciones de tipo meridional en la llamada zona de los jándalos ${ }^{3}$. Sin entrar en mayores detalles, ajenos a mi interés actual, tendríamos un dominio escindido en dos grandes sectores que hablan de una geografía lingǘstica antigua, por más que ahora vaya siendo sustituida en muchos sitios por una sociolingǘstica en la que podemos rastrear la altura social de los fenómenos. Desgraciadamente no se puede comparar la información del atlas regional con el Atlas Lingütstico de la Peninsula Ibérica" porque en éste no hay ninguna palabra que remonte a un étimo latino con $\mathrm{F}^{-5}$. Sí hay casos en los que al sonido

1 "Revista de Filología Española», XXIII, pp. 225-254 y 337-378.

"Archivum", IV, pp. 435-437.

3 Testimonios de Herrera de Ibio (S ro6), Tresviso (S ro8), Orejo (S 205), Abiada (S 3r3).

- Tomo I, Madrid, 1962.

- Si dentro de estas posibilidades admitiéramos la palabra ahogarse (mapa 13), se conservó la $[h]$ en los puntos 400,404 y 407 de la provincia. 


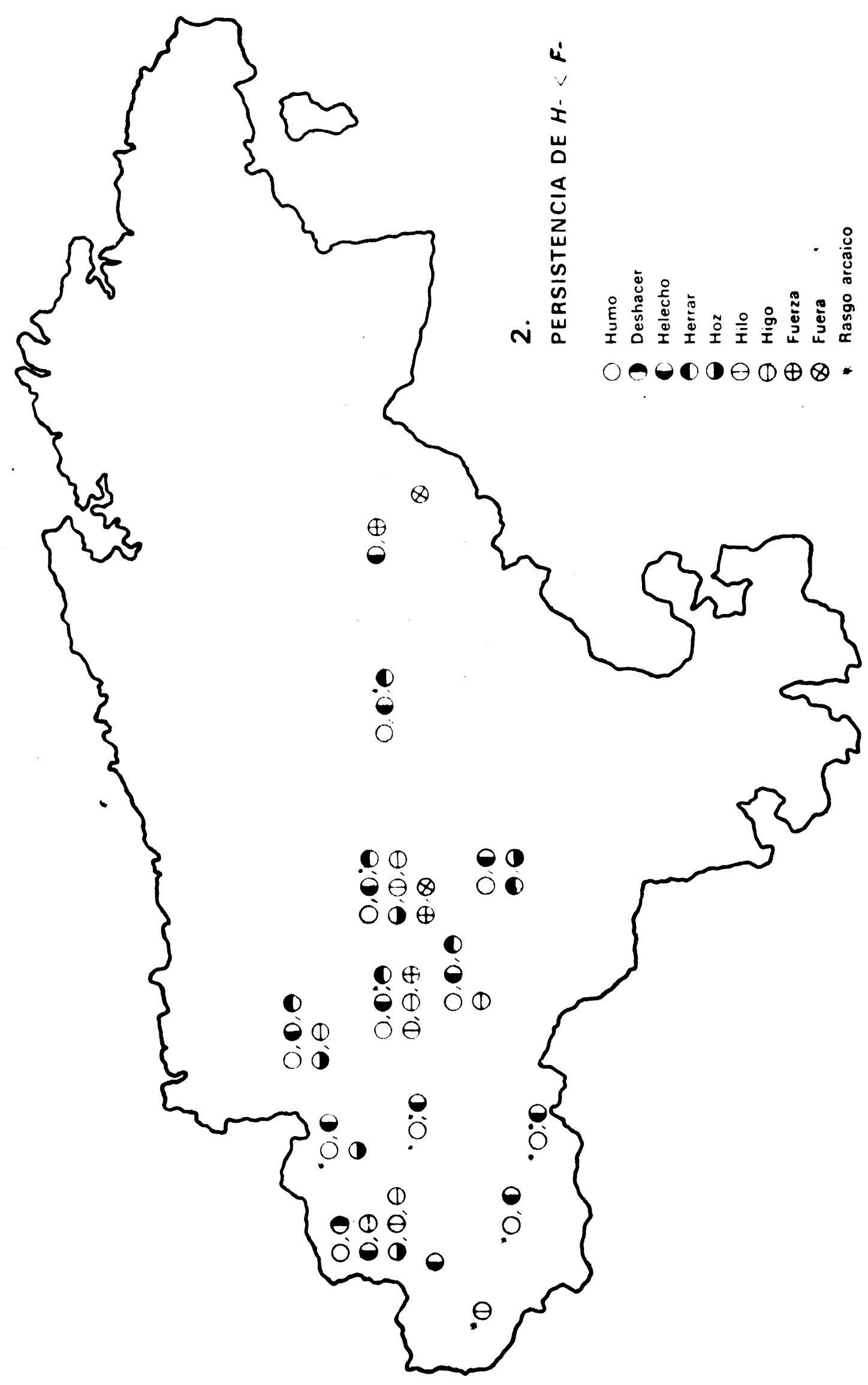


castellano $[x]$ puede corresponder una aspiración: tal el mapa 6, muy poco significativo, porque abeja no es término general en la provincia, o el mapa II, porque grijo 'aguijón da la abeja' tampoco lo es. Si nos fijamos en un mapa de uniformidad léxica, veríamos que los datos no permiten sino afirmaciones demasiado amplias: la palabra aguja (mapa I2) se articuló con $[x]$ en seis puntos del centro-oriente santanderino; con $[h]$ en cuatro del occidente y con $\left[\begin{array}{l}h \\ x\end{array}\right]$ en el más meridional de los que se incluyen; los mapas 32 (caja), 4I (cejas), 44 (cerrojo), 75 (eje) coinciden con el anterior salvo en el punto aislado con archifonema: ahora la realización es jota; mientras que en cojo (mapa 50) $\left[\begin{array}{l}h \\ x\end{array}\right]$ aparece en el punto $402^{\prime}$. Sin embargo, el atlas de nuestro pequeño dominio muestra cómo la situación descrita en la monografía de Rodríguez-Castellano está en franco retroceso: mi cuestionario, en su parte fonética, tenía II palabras con étimo $\mathrm{F}$ - y en ningún pueblo se ha comprobado la persistencia de manera uniforme: en unos casos porque la presión del castellano ha eliminado cualquier dialectalismo (hierro, fuego) o ha reducido los rasgos regionales a trazos a punto de extinción (hilo, fuerza, fuera); resulta entonces que el fenómeno subsiste con gran vitalidad en un pequeño ámbito del centro-occidente de la provincia, mientras que el tratamiento parece muy restringido en la región de Villacarriedo y es un puro arcaísmo en el arco formado por Espinama-Pesaguero. Si por un lado asistimos al retroceso y desaparición de un arcaísmo, por otro vemos confirmarse un viejo postulado de la geografía lingïística: "cada palabra tiene su historia particular" 2 No podemos caer a estas alturas en la creencia del carácter imperativo e inesquivable de las llamadas leyes fonéticas: nuestra pequeña parcela ha venido a probar dos asertos fundamentales de la lingüística, y, cuando la erosión del dialecto alcanza grados extremos, contemplamos cómo hay términos incapaces de subsistir, mientras otros se mantienen tercamente. Pero en cada caso, los enfrentamientos con la singularidad individual de las palabras, no con la abstracción llamada ley fonética.

En cuanto a la presencia de $h$, o sus variantes, donde el castellano normativo tiene $[x]\left(<-C^{\prime} L_{-},-D Y-,-I . Y-\right)$ las áreas no coinciden con las que remontan a F-, pues ahora la aspiración se da en Celis, La Hermida y Bárcena Mayor, así como en Villacarriedo, donde tan pobremente se documentó $\mathrm{F}$ - $>h$, mientras que ha desaparecido de Tresviso, pue-

1 Como en otras veces, el dibujo de las palabras en el mapa carece de criterio y no es posible decidir cuál es la respuesta que corresponde al punto 402 y cuál al 408 .

- KARI JABERG, Geografía lingülstica. Ensayo de interpretacion del "Atlas lingütstico de Francia" (trad. de A. Llorente y M. Alvar), (iranada, r959, p. 20. 


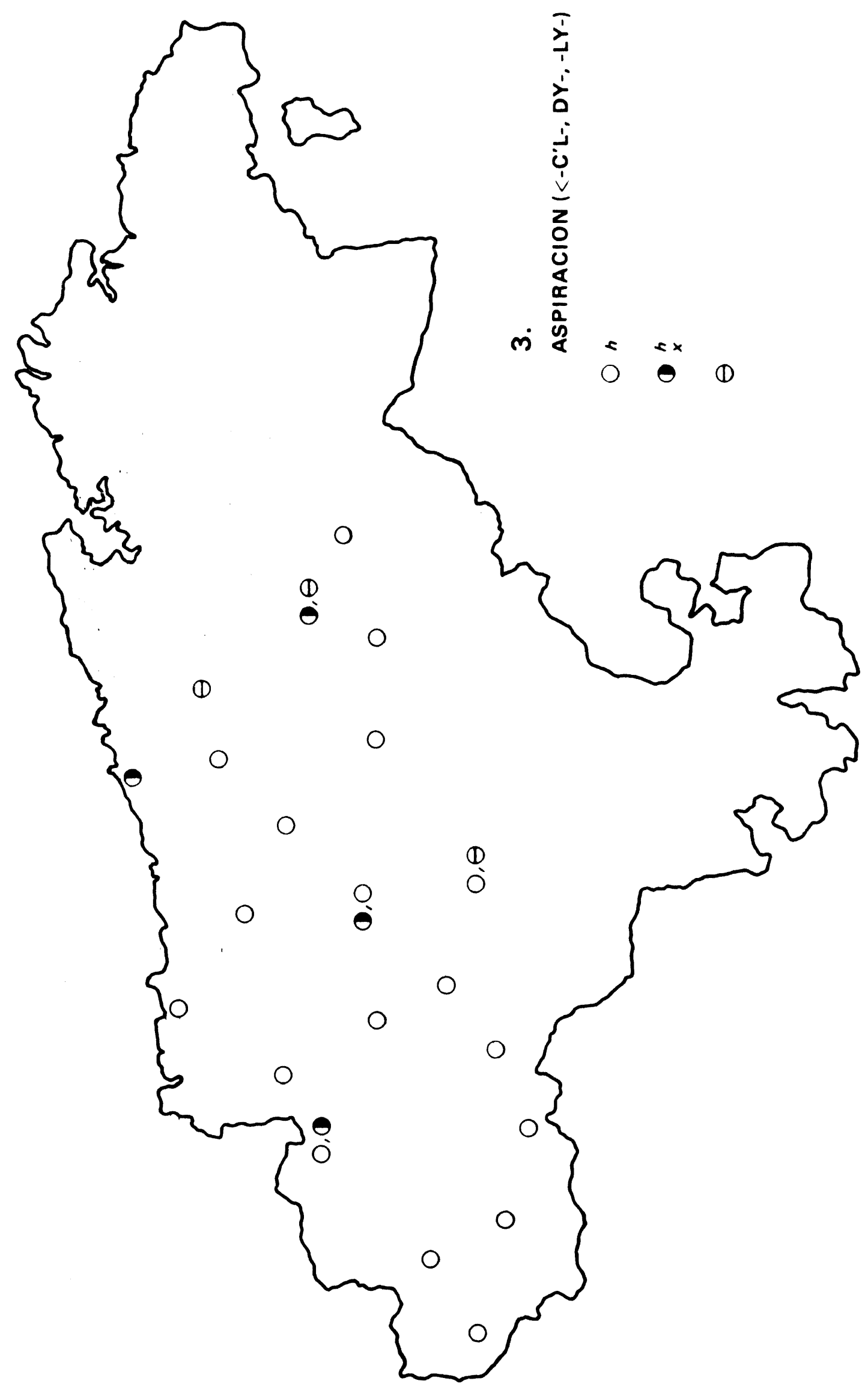


blo en el que $h\left(<\mathrm{F}^{-}\right)$tenía la máxima vitalidad. Nos encontramos, pues, con una situación muy compleja y que refleja algo de los que ha sido la vida de nuestra propia lengua: $\mathrm{F}->h->\varnothing$ indican procesos de castellanización, según normas digamos cortesanas (Burgos, Toledo); lógicamente, a mayor antigüedad de la evolución, corresponde pérdida de la aspirada. Por el contrario, la aspirada [h] procedente de -C'L-, -DY-, y -LY- es resultado más reciente de $z$ o $z$ desaparecidas en el siglo xvI ${ }^{1}$. Los dos mapas no cinciden porque remontan a evoluciones lingüísticas diferentes por más que hayan llegado a la misma situación en otros ámbitos lingüísticos. En el nuestro, $h-(<\mathrm{F}-)$ indica arcaísmo medieval muy antiguo, mientras que $h\left(<-C^{\prime} L_{-}\right.$, DY-, $\left.-L_{-}-\right)$ es un rasgo del siglo XVI o todavía posterior. Si el castellano medio llegó a $\varnothing$ y a $[x]$ respectivamente, las hablas santanderinas caminan hacia los mismos resultados, pero con una marcha muy atemperada. Queda aparte Tresviso con su $[h]$ y su $[x]$ que muestra el arcaísmo $\mathrm{F}->h$ y la desaparición muy tardía de $z, z$ (arcaísmo también con respecto al español del siglo xvi): cuando la palatal fricativa desapareció del sistema, se cambió por la $[x]$ castellana, que ya era una articulación totalmente estable, y diferenciada con respecto al cero fonético. De este modo, la casilla de la aspirada estaba cubierta por un fonema / $h /$ establecido sincrónicamente porque, además, tal situación procedía de una historia bien definida; el paso $\ddot{s}, z>[x]$ no fue gradual, sino brusco, de tal modo que no hubo evolución sino sustitución una vez que el castellano ya tenía $[x]$. Así, sobre un plano moderno, $[h]$ era conocida, pero muy diferenciada de $[x]$. Por eso $h$, rasgo conservador, no se ha confundido con una innovación suficientemente diferenciada.

No escasea la bibliografía sobre el yeísmo peninsular. Sin embargo, las noticias que teniamos de Santander no eran, precisamente, valiosas. Tan gran investigador como Amado Alonso tuvo que contentarse con esta pobre información: "En la montaña de Santander también existe [el yeísmo], más frecuente en las variantes campurrianas y valdigreñesas que en las pasiegas y occidentales, según García Lomas [...]. La ciudad de Santander es también casi del todo yeista». Y, páginas adelante, al caracterizar la articulación dice que "el yefsmo de Santander $y$ el de Valladolid suenan $y{ }^{2}{ }^{2}$. Todo lo que sablamos era, por tanto, impreciso y referido a unos informes de I922, facilitados por quien

1 Sevilla, macrocosmos lingüistico, apud. "Esstudios filológicos y lingüdsticos" (homenaje a A. Rosenblat). Caracas, 1974, pp. 21-24.

- La "ll y sus alteraciones en España y América ("Estudios dedicados a Menéndez Pidal", II, 195I, pp. $5^{8}$ y 63, respectivamente). 


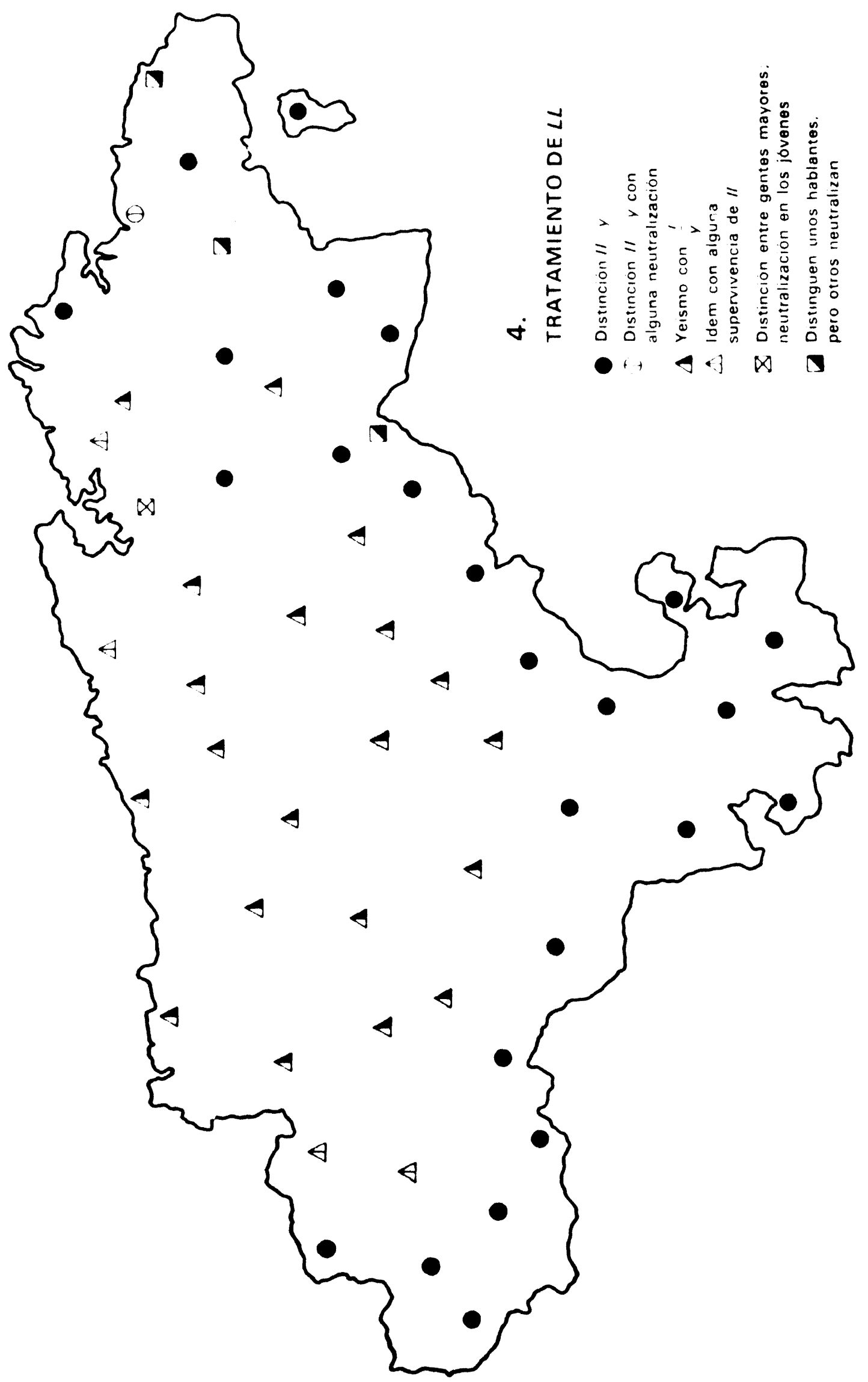


no tenía formación lingüística. Ahora, las encuestas de nuestro Atlas permiten formular las cosas de manera mucho más justa, pues si precisan el tipo de articulación de la $y$ (muy abierta e incluso $i$ semivocálica) ${ }^{1}$, señalan también el carácter social de la distinción (entre gentes mayores, entre mujeres) o la persistencia de algunos caracteres totalmente en retirada (distinción en pueblos yeístas; yeísmo en los distinguidores) y ayudan a un trazado geográfico lleno de rigor, en tanto el $A L P I$ nos deja en una situación de duda: toda la provincia es distinguidora, salvo los puntos 400 y 406 que son yeístas (mapas 29, caballo; 37, castillo) o en los puntos 400, 406 y 4 II que neutralizan en $y$ e incluso pierden la palatal central (cuchiu, punto 4II). Desde el punto de vista de la geografía lingüística se ve con una portentosa claridad que la conservación de la $l l$ forma un arco por el sur de la provincia con estribos de apoyo en los extremos orientales y occidentales y alguna salpicadura no lejos de Santander; o dicho de otro modo, los procesos de neutralización $l l=y$ se cumplen como resultado de una irradiación lingüística producida desde la capital: todas las gentes de Santander fueron yeístas, $y$ este proceso igualador se va cumpliendo de una $\mathbf{u}$ otra manera, pero indefectiblemente ya. Situación que ha culminado tantas veces en el mundo hispánico: las zonas rurales son distinguidoras, mientras que las grandes aglomeraciones urbanas pierden la $l l$ y propenden a la igualación ${ }^{2}$.

Otra cuestión tardíamente estudiada es la de la metafonía vocálica. También fue Rodriguez Castellano quien llamó la atención sobre el carácter del fenómeno en la provincia de Santander ${ }^{3}$ : "ocupa [...] una corta extensión en la parte sur de la provincia, en torno al Valle de Pas [...]. Los pueblos de los que poseemos información son [...]: Vega de Pas, Resconorio, Carrascal, San Pedro del Romeral, Bustantegua, San Roque de Río Miera y Veguilla" (p. 237). En el ALPI hay metafonía en los mapas 8 (abuelo) con su (a)güilu (408 Bustantegua, 407 Vega de Pas, 4II Resconorio), 9 (acero) con su aciru (4II) y 59 (cuero) con su cuiru $(408,407,4 \mathrm{II})$, cierto que no en todos los casos previsibles, con lo que se manifiesta la restricción que puede tener el fenómeno;

1 Cf. Hugo Plomteux, Questione di metodo ("La ricerca dialectale", I, 1975. pp. 533-539).

- Geografía y sociología lingüisticas en el español insular y Notas sobre el yeismo y la oposición de elle y ye, en los Estudios canarios, t. I, Las Palmas, 1968 pp. 33 y $79-80$.

${ }^{3}$ Algunas precisiones sobre la metafonia de Santander y Asturias ("Archivum", IX, 1959, pp. 236-247). 
los materiales del atlas que hemos realizado muestran la vitalidad del fenómeno en Vega de Pas, pero no de una manera absoluta; en los cien primeros mapas de la obra documento las metafonías siguientes:

é ... u: wicu 'hueco', güisu 'hueso', llinu '1leno', caldiru 'caldero', cuiru 'cuero', becirru 'becerro'.

á ... u: gätu 'gato', ermänu 'hermano', gränu 'grano'.

Sin embargo, no hay ningún caso por inflexión de $-e$, ni de - $o$ en las palabras fleco, ciego, ojo, viejo, poyo, hoyo, pecho, maestro, pelo, potro, pollo, toro, helecho, hierro, fuego, luego, lomo, nuevo, bolso (cito por el orden de los términos en el cuestionario). Comoquiera que no hemos encontrado ni un solo caso de metafonía en San Pedro del Romeral ni en Veguilla, hay que creer que el fenómeno está en total retroceso con respecto a lo que señaló Rodríguez Castellano, ya que en San Pedro del Romeral tuvimos informantes de mucha edad, lo mismo que en Veguilla, y que en Vega de Pas hicimos encuestas con muchísimas personas en las cabañas más aisladas y en algún caso rodeados con varios vaqueros (hombres y mujeres) que discutían entre sí las formas que les proponfamos. Mi información es más restringida que la de Penny ${ }^{1}$, pues no encontré, sistemáticamente, $\delta \ldots u>\dot{u} \ldots u^{2}$, ni, como queda dicho, metafonía producida por $-i$ final. Creo que el atlas representa 1a situación actual del habla, sin exageraciones dialectales: transcribílo que of y aun formulé preguntas directas cuyo resultado no fue mucho mejor que el procedimiento ordinario ${ }^{3}$.

He aquí, pues, cómo unos pocos temas suscitados por la investigación dialectal nos ha mostrado la complejidad de la provincia de Santander. Podríamos seguir aumentando nuestra perspectiva con otros no señalados, tales como el tratamiento de $-e$ y $-o$ finales, la inestabilidad de las vocales átonas, la suerte de la $-d$ - intervocálica, la neutralización de $l$ y $r$, etc. Amplio panorama en el que la distribución geográ-

1 El habla pasiega: ensayo de dialectologia montañesa. Londres, 1969. No me parece justa su transcripción de $a$ palatal con signos infrascritos que puede tener interpretación ambigua; creo preferible $\vec{a}$, con diéresis, que indica vocal palatal, incluso en la ortografía oficial de alguna lengua. En cuanto a que el cuestionario del Atlas de Aragón proceda del que se empleó en el $A L P I$ (p. 37), habria muchisimo que hablar.

- Sblo en Villacarriedo transcribí un puyu 'poyo'; en Vega del Pas, truncu, repullu, ulmu, $y$, en Veguilla, cogullu.

- Por ejemplo, en cuévano nadie identificó cuivanu, por más que también conociera cuenu. 
fica, la altura social de los fenómenos o las relaciones con otras hablas o dialectos nos mostrarían, en esta pequeña superficie, un mundo abigarrado y complejo.

\section{Atlas y diccionarios}

Acaso nada de los que venimos exponiendo se pueda ver con tanta claridad como en la ordenación del léxico. Al vocabulario de la provincia de Santander se han dedicado estudios de valor muy diverso, y todos con criterios que distan mucho de darnos la vida de la lengua.

En esos trabajos hay unos en que la recogida de materiales se ha hecho de manera ocasional, cuando no caprichosa. Cronológicamente, son los que siguen: Eduardo de Huidobro en su libro Palabras, giros y bellezas del lenguaje popular de la Montaña (Santander, 1907) reunió una colección de más de seiscientos términos sacados de las obras de Pereda; él mismo se encargó de editar una veintena de páginas ${ }^{1}$ que Juan González Campuzano había allegado con más pretenciosos fines. Huidobro reordenó los materiales de González Campuzano ( Juan Sierrapando en la literatura costumbrista): eliminó las voces que procedían de su libro de 1907, quitó otras que no eran santanderinas, añadió algunas notas, cambió el título a la compilación y nos ofreció un conjunto nada florido. En la gavilla hay términos de mucho más amplia geografía (agorar 'empollar', ajumarse 'embriagarse', aldaba 'pestillo', etc.), otros que son meras variantes fonéticas (aguantis 'paciencia', alreguedor 'alrededor', anfiletero 'alfiletero', etc.), otros que presentan rasgos morfológicos de carácter común (ajuir 'huir', apasear 'pasear', arrejuntar 'reunir, juntar', etc.); de este modo las pocas páginas aún se reducen en mucho. Pensemos en las limitaciones de Campuzano y en el prurito, nada objetivo, de Huidobro para manifestar las excelencias de su trabajo frente al que le encomendaron revisar.

Por su parte, José María de Cossío, con el modesto título de Aportación al léxico montañés ${ }^{2}$ presentó en siete páginas algunas muestras del vocabulario de 'Tudanca. Cierto que los datos son escasos y que las etimonologías que propone, con frecuencia inexactas.

Ein I933, H. Alcalde del $\mathrm{Río}^{3}$ presentó un trabajo de no mayor

1 Apuntes para un vocabulario montañes. Revisadas $\mathrm{y}$ anotadas por E. DE Huidobro. ("Boletín de la Biblioteca Menéndez Pelayo», II, r920, pp. 3-ro y 59-68).

2 "Boletín de la Biblioteca Menéndez Pelayo", IX, 1927, pp. I15-122.

- Contribución al léxico montañés. Santander, 1933 [3 I páginas]. 
empeño, que fue reseñado por Fritz Krüger ${ }^{1}$ con estas palabras, en las que, brevemente, se denuncian las limitaciones de la aportación: "Seine Veröffentlichung bietet ein wertvolles Inventarium von Wörtern und von Sachen des kantabrischen Gebirges (insbesondere aus dem Valle de Pas und der Liébana), das die bekannten Vokabulare von Pereda, Huidobro, García Lomas und J. González Campuzano wesentlich ergänzt».

Como se ve, y a esto tendré que volver, las breves compilaciones a que he hecho mención sólo muy parcialmente pueden afectar a la vida del lenguaje en la provincia de Santander: se limitan — y hago caso omiso de su penuria - a zonas muy arcaizantes del dominio ('Tudanca, Liébana, Pas) con lo que no disponemos con ellas sino de unas reliquias venerables, y nada más. Que es necesario salvar las antiguallas antes de su desaparición, no seré yo quien lo discuta, pero un atlas es mucho más que eso: si en la mente de Gilliéron nació como un principio para mostrarnos la vida del lenguaje, el estado actual -aún no historiade una realidad y los principios activos que hacen actuar a ese cuerpo vivo, evidentemente, poco sacaremos en limpio recogiendo unos materiales arqueológicos que servirán para una diacronía inoperante ya, no para una sincronía válida para nuestra circunstancia de hoy, y válida también para los futuros investigadores de la lengua. Creo que estas conclusiones son justas y precisas; los estudios modernos de geografía lingüística han mostrado de manera suficiente cómo en los atlas se encuentran -y más que en los diccionarios- aquellos propósitos que Leo Spitzer quería buscar en el estudio de cualquier lengua: el elemento vital, la organización que el hombre da a sus datos, la comprensión del trabajo creador inherente al quehacer lingüístico ${ }^{2}$.

Mencionamos, por último, en este apartado, dos artículos de J. Calderón Escalada, cuyos títulos muestran el carácter de acopio con respecto al Diccionario académico ${ }^{3}$. Se trata de unas simples enumeracio-

1 "Volkstum und Kultur der Romanen", VII, 1934, pp. 371-382.

2 Atlas linguistique ou Grammaires-dictionnaires-textes? ("Revue International des Études Basques", XIX, I928, p. I75).

- Voces, en su mayor parte nombre de cosas, de uso corriente en estos valles altos de la provincia de Santander, que no estan recogidas en el Diccionario de la Lengua Española ("Boletín de la Real Academia Española», XXV, 1946, pp. 379397) y Voces, en su mayor parte de cosas, de uso corriente en los valles altos de la provincia de Santander, que no están recogidas en el Diccionario de la Academia ("Boletín de la Real Academia Española», XXXIII, 1953, pp. 295-304). A estas papeletas habria que añadir alguna otra referencia bibliográfica de carácter afín, como las de G. M. Vergara que describo en los números 107-109 de mi Dialectologia española. Madrid, I962. (La 108 tiene referencias a Santander). 
nes léxicas sin ningún tipo de aclaración o sin el menor asomo interpretativo. Bástennos unos pocos ejemplos: alcerón 'planta que crece entre los sembrados', barullón 'dícese del que, por hacer mucho, lo hace mal', becerrero 'ayudante del vaquero', boquera 'agujero del pajar por donde se tira el cebo al ganado', caballuna 'boñiga de caballería', cagalita 'excremento de la oveja', etc. El segundo de sus artículos (I48 voces) tiene las mismas características, con sus apartijo 'rincón separado por setos', berbajo 'brebaje', calostrizo 'derivado de calostro', esbalagar 'deshacer el montón de bálago', llueca 'gallina llueca' [sic], trigal 'tierra sembrada de trigo', etc.

Ciertamente, no es mucho de lo que podemos esperar de estos trabajos, que no dudo en calificar de beneméritos, pero en los que encontramos los defectos que siempre se han señalado en los aficionados: falta de sistema, imprecisión geográfica, convertir en categorías las documentaciones ocasionales, referencia - ínica- al Diccionario de la Academia con ignorancia de cuanto en él no conste. Pero nuestro propósito, el propósito de cualquier atlas, no es entrar en competencia con unas aportaciones de valor concreto y limitado, sino un interés muy diferente. Digámoslo con palabras que ya van siendo tópicas: recogida uniforme de datos, con distribución homogénea y por especialistas, para obtener de ese modo la visión espacial y simultánea de los hechos de lengua, la uniformidad de criterio en la recolección, la exactitud de los datos facilitados, el rigor de las transcripciones. Sean estas palabras justificación de una crítica que no pretende desdeñar nada, sino justificar los muchos porqués de una obra que se ha emprendido.

Por eso tampoco podíamos esperar demasiado de trabajos científicamente elaborados, pero muy restringidos en cuanto a su alcance. Pienso, por ejemplo, en los estudios etimológicos del gran romanista Leo Spitzer: poco importa que su étimon del santanderino borcil 'cubil' 1 se haya discutido $^{2}$, pues con mucho dispondríamos de informes seguros sobre una sola voz, y sólo eso; lógicamente es preferible saber que el gran teórico del idealismo ha acertado al explicar de modo satisfactorio el montañés asubiar 'uncir' como procedente del latín ad $+\mathrm{s} u \mathrm{~b}+$ o b vi a re, que deja herederos de la forma no prefijada en el propio santanderino uviar 'venir, llegar el ganado a reunirse bajo techado en los temporales' ${ }^{3}$, o que rámila, y su variantes, en la acepción de 'gar-

1 "Revista de Filología Española", IX, 1922, p. 67.

2 Vicente Garcia de Diego, en la revista citada en la nota anterior, pp. 67-68.

3 Santand. "anubiar"; esp. "sobaco"; esp. "sobón" ("Revista de Filologia Espaoñla”, XI, 1924, pp. 70-72). 
duña', tenga algo que ver, lo que no me convence completamente, con r a c e $\mathrm{mu} \mathrm{s}^{\mathfrak{2}}$. Después de todo no tenemos sino un parvísimo conjunto de términos, pero nada para la interpretación que exige el léxico, muy rico e inesperado, que debemos inventariar en nuestra provincia. Y aquí, también, el atlas puede proyectar hasta límites insospechados lo que en los estudios etimológicos no es sino pobreza o austeridad. $\mathrm{Y}$ sólo entonces cobrará cabal sentido aquello que se ha querido explicar. En efecto, para derivar borcil de por c u, García de Diego señaló serios incon. venientes, pero la geografía lingüistica regional nos hace dar un margen de fiabilidad a lo que Spitzer habia intuido, pues junto a cubil, chonera, corte, cortino, cortijo, corticho, etc., en bastantes puntos del atlas hemos encontrado borcil como 'pocilga para la piara'. En cuanto el étimon de asubiar, nuestra información, muy rica, viene a confirmar la hipótesis comúnmente aceptada, e incluso facilita formas que hubiéramos esperado: además de asubiar y asudiar hay asuyar(se) y alteraciones de la idea de '(de)bajo', una vez que subtus dejó de ser operante (atubiase, que hace pensar en un sutubiase previo, y también registrado por nosotros). La alternancia $\mathrm{sub} / \mathrm{subtus}$ se comprueba en la doble serie asubiar, asudiar, asuyo (muy viva) frente a los derivados sutubiase, atubiase, sotubio (mucho más restringida); por el contrario, no parece tan firme pensar en y u gu, por cuanto ensobiar 'uncir' y desensobiar 'desuncir', sólo se documentan en Pesaguero.

Por último, rámila como 'garduña' no presenta variantes, por 10 que poco puede ayudar el atlas a resolver la etimología sí confirma la correcta acentuación de esta voz, y su variante rohmilla 'marta' da la razón a Corominas ( $D C E L C$, s. v. rámila) frente a una mala transcripción de García Lomas. De cualquier modo, no parece aceptable el étimon $\mathrm{r}$ a ce m us.

Todos estos motivos, y algún otro que aún tendré que aducir, no serían sino muestras aisladas de hechos que podemos investigar todavía. Pero pensemos que los comentarios en torno a esas poquísimas etimologías cuentan con las posibilidades que brinda el atlas: tanto para enriquecer la información como para hacernos ver el caminar hacia la muerte de un léxico patrimonial. En este sentido nada que resulte más ilustrativo que alguna parcela del cuestionario referida al léxico rural.

La provincia de Santander cuenta con un diccionario nada desdeñable, el de Adriano García Lomas. La primera edición es de I922 y la

1 Notes étymologiques, "Revista de Filología Española", XIV, 1927, pp. 253-254. 
segunda de $1949^{1}$. Lógicamente, ésta amplió mucho los materiales allegados en un principio. Un diccionario no es un atlas, tiene coincidencias con él, pero también enormes discrepancias, según vamos a ver. Para redactar el cuestionario que íbamos a utilizar en las encuestas, despojé íntegramente la segunda edición de la obra y de este modo, hemos preguntado por la información que creimos válida del léxico. Sin embargo, los resultados obtenidos no siempre concuerdan con el esfuerzo y las esperanzas que hemos invertido. Cierto que el resultado negativo puede indicarnos procesos de modernización y nivelación, pero - también - puede indicarnos que aquello que se habia allegado como montañés no lo era. O, acaso, García Lomas había convertido -y es mal de todos los aficionados locales - en categorla lo que no pasaba de ser anécdota, realización ocasional o motivo personal. Porque es fácil decir que un determinado ámbito se ha nivelado conforme a las formas de la lengua standard; esto puede ser verdad, y la provincia de Santander muestra bien a las claras la pérdida de una vida tradicional: pensemos en la sorprendente pobreza que tiene todo lo que se relaciona con la elaboración del queso; el desarrollo de una técnica impuesta por centrales y cooperativas ha hecho que se olviden los principios tradicionales, y la terminologfa del expremijo, del cuajo, de la cuajada, del requesón o de la encella es muy monótona contra lo que hubiéramos querido encontrar. Pero si esto es cierto, no lo es menos que los dialectos no se extinguen con tanta prisa como muchos creen: para mi resulta harto ilustrativo que el habla de la Isla de Francia o del Orleanesado sea hoy más dialectal que en tiempos de Gilliéron, según ha mostrado Mme. Simoni-Aurembou ${ }^{2}$. O dicho de otra forma, para mí más cierta: el dialectólogo de hoy ha recogido con más cuidado su información de lo que pudo hacer Edmont al quebrar el siglo xx; las hablas populares estaban -y están - ahí, lo que ocurre es que el explorador de un atlas general pasó junto a los dialectos sin entrar en algunos de ellos ${ }^{3}$ $\mathrm{Y}$ si esto ha sido así nada menos que en las regiones más influidas por la irradiación de París, ¿no podremos creer que entre nosotros ha po-

1 Estudio del dialecto popular montañés. Fonética, etimologias y glosario de voces. San Sebastián, 1922. El lenguaje popular de las montañas de Santander. Fonética, recopilación de voces, refranes y modismos. Santander, 1949.

2 L'Evolution des patois de l'Ile-de-France depuis les euquetes d'Edmont: Commentaire de quelques cartes ( Actele celui de-al XII-lea Congres International de lingvistic ‘ şi filologie romanica», t. II, I97I, pp. 215-233). Cf. Estructuralismo, geografia lingüistica y dialectologia actual (2.a ed.). Madrid, 1973, pp. 177-178.

- PIIRRE GARDETRE, L'Atlas linguistique et ethnographique du Lyonnais ("Bibliotèque du Français Moderne», p. I). 
dido ocurrir algo parecido? Entonces creo que deberemos proceder con cautela: hay pérdida de elementos dialectales, pero hay dialectalismos que afloran tan pronto como proyectamos el cuidado de nuestras pesquisas.

Ante esto, formulo mis reservas acenca del valor de los diccionarios dialectales, por más que ya he declarado su utilidad. Creo que al considerar el de García Lomas con los resultados que derivan del atlas, hemos de reconocer varios hechos que iré describiendo con cierto orden.

La lengua ha perdido parcelas de su léxico porque se ha perdido también la vida tradicional. Pero el diccionario recoge sus informes sin discriminar; normalmente falta localización geográfica precisa, faltan consideraciones sociológicas y se ignoran los principios de la propia biología lingǘstica. Tenemos ahí una colección de palabras y, con frecuencia, sólo eso. El atlas nos da la vida: con sus altibajos y sus claudicaciones, con su vigor y la fuerza de su eclosión, con su verdad sin disimulos. Poco importa que un término sea trivial o se repita o se ignore: es el conjunto lo que en definitiva nos va a valer. El autor del diccionario tiene que salvar antiguallas, términos que vo se perpetúan, realidades que fueron, cuando no ha de mejorar una vida que se muestra monótona. Con frecuencia, por encima de todo está el uhonor» del dialecto. Para nosotros nada de esto afecta a la misión de colectores: tanto vale un término viejo como otro nuevo, la rareza como la trivialidad y sabemos que tan creación es lo que hicieron nuestros abuelos hace siglos como lo que está naciendo bajo nuestras miradas. Importa la vida, no la arqueologia.

Por otra parte se me hace dificil que muera un término en unos pocos años, y pocos son para la vida del lenguaje algunos menos de un siglo. No puedo creer que una áspera lija haya raspado toda la rugosa superficie de una lengua sin que entre las grietas se haya podido salvar tal o cual término que créamos vivo hace poco. Porque, en efecto, un diccionario publicado en 1922 remonta fácilmente a situaciones lingüusticas que fueron generadas en 1850: informantes provectos pudieron dar una imagen obsoleta ya por esos años de I920. Sí, aunque tenemos otros datos que nos hablan contra los riesgos de esta generalización. Como en todos los atlas que he organizado, el uso del cuestionario no quiere decir que postulemos por una traducción del término académico, sino que -indirectamente- planteamos la cuestión que provoca la respuesta buscada. También ahora organizamos ast nuestras encuestas, pero, junto al término de la lengua común poniamos las previsibles respuestas según el diccionario montañés. La sorpresa era grande: la voz 
"dialectal» no aparecía; entonces preguntábamos por ella y resultaba ser desconocida. Muy al azar voy a seleccionar unos cuantos ejemplos : en el diccionario dialectal, natadero, rentiru, covio son los nombres de la 'vasija en la que se pone la leche al sereno para que se forme la nata', preguntando según esta explicación, recogimos olla, caldero, tartera de barro, puchero, cazuela, barreñon, jarra, hervidor, cubo, cudio, puchera, cacharra, marmita, cantimplora; insistiendo en estos hechos, garamasto 'nabo silvestre' no aparece en ningún sitio, mientras documentamos nabo silvestre, mastrancho, nabo tallo, quitameriendas, ajo d'antojil 0 , para remediar enumeraciones que llegarfan hasta la impertinencia, el 'brote de las plantas' no es llueto en ninguna parte, ni 'pelar un fruto' se documenta nunca como brullar ${ }^{2}$.

$\mathrm{Si}$ en muchísimas ocasiones no hay ninguna correspondencia entre el diccionario dialectal y el atlas, otras podemos comprobar la pretensión de salvar antiguallas que el lexicógrafo ha tenido o, cuando menos, de recoger términos que apenas si tienen vida. Para dar cierta coherencia a estas anotaciones me voy a fijar en unos casos de significados muy concretos: marocazo es, según Garcla Lomas, 'topetada', nosotros recogimos carnerá, escarnerazo, mochazo, testarazo, castrazo, castronazo, topetazo, mochada, trompazo, y sólo en un punto el término propuesto; el 'castañazo bravío', según refiere García Lomas, recibe los nombres de mayo y mayuelo; el segundo - con los datos allegados in situ- no aparece nunca, sin embargo, no son desconocidas connotaciones como castaño montesino, castaño silvestre, castaño pilongo, etc.; en consecuencia con los hechos anteriores, la 'castaña bravia' no es nunca mayuela. Las formas desorizar o desbordizar para designar el 'desprenderse el erizo de la castaña' han llegado a nosotros bajo formas modificadas en desgorizar (408, San Pedro del Romeral) y deserizar (I02, Torrelavega; 108, Tresviso; 304, Camaleño) mientras que no escasean otras denomi-

1 Cito las palabras por su documentación según el número que los pueblos tienen en el atles.

- Siquiera en nota, debo señalar la utilidad del atlas desde un punto de vinta práctico: la visión simultánea, rápida y ordenada de los materiales permite la identificación de los hechos que buscamos. En este sentido me parece ilustrativo mostrar, por más que no pueda compartir el criterio, que la Peninsula Iberica soblo está representada por el dominio catalán (único del que se utilizó un atlas) en el trabajo de WETJNEN y Arrorer. The Wheel in the Atlas Lingwarum Europae. Heteronyms and semantic Density ( BBijdragen en Medelingen der Dialectencommisaie van de koninklijke nederlandse Akademie van Wetenschappen te Amnterdamn, XIIV, 1974, pp. 5-I5). 
naciones más o menos específicas, pero que tienen -algunas de ellasun marcado arraigo tradicional, junto a formas no discriminatorias (caer, estar maduras) hay otras bien marcadas: esconchar, estar calentias, desnojar, desordinar, desnonjar. La 'piel de la castaña' permite documentar concho únicamente en cinco puntos de la provincia (ro5, Io6, I08, 407, 408) o, por último, el 'endrino' sólo persiste como andriniego (según García Lomas, andriniega, que para nuestros formantes es la 'endrina') en los puntos 500, 50r y como brunal en los ro4, I07 (en el lexicógrafo, brunero nunca recogido), mientras que la sinonimia no es nada despreciable: andrino, espino, cerojo, andrinal, andrín, ciruelo malo, ciruelo andriniego.

Creo que con estas calas, deliberadamente restringidas, podemos comprobar los resultados tan heterogéneos que se obtienen al comparar el vocabulario fosilizado en una compilación lexicográfica y la vida fluyente que el atlas permite recoger ${ }^{1}$. Que la desaparición de una forma de vida acarrea la muerte de las palabras es archisabido. $Y$ para nuestra provincia me permitiría señalar la desaparición casi absoluta del cultivo del trigo, y con él la pérdida de una parcela riquísima del vocabulario español, o la imposibilidad de poder hacer hoy nada comparable a lo que ya va por el medio siglo llevó a cabo G. Camino y Aguirre con sus Hilanderas y telares en la Montaña ${ }^{2}$. Las cosas han cambiado y la lengua refleja las mutaciones. Esto es cierto, pero también lo es que un léxico 'más estable (nombre de la bestezuela, de una fruta local, de cosas que no cuentan en el comercio) no desaparece de la tarde a la mañana sin dejar rastro. Frente a esa "desdialectalización» que las hablas vivas parecen tener frente a los archivos de palabras, está la conservación pertinaz y terca de voces que no se resignan a morir. Por eso dudo mucho de que valgan demasiado las generalizaciones con que tropezamos en los diccionarios ${ }^{3}$. $Y$ voy a poner un ejemplo sacado de nuestro propio atlas. Carlos Alvar, que con José A. Mayoral y conmigo, ha hecho

1 No se olvide algo sabido desde hace muchisimo tiempo: "Die beste und bequennste Kontrolle des Atlas ist diejenige durch sich selbst» (E. Tappolet, Bedeutung der Sprachgeographie, en Aus romanischen Sprachen und Iiteraturen.

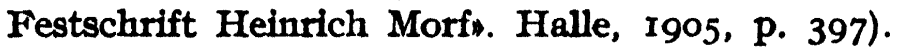

2 "La Revista de Santander", 1932-33.

8 Cf. el articulo de Spitzer ya citado (p. 94, nota 2) y que tan negado ha sido por la investigación pasterior; en este momento interesa la p. I73 del gran romanista.Un atlas es una tarea muy costosa, cierto, pero ¿y un diccionario como el que postulaba Spitzer (p. I74)? Tenemos ejemplos bien próximos. Por lo demás, manejar preferencias sobre hipótesis que probablemente no se formularán nunca, cuando menos, carece de sentido. 
todas las encuestas de la provincia, ha publicado un curiosísimo estudio motivado, precisamente, por los cuestionarios santanderinos ${ }^{1}$. Hay un pasaje de Rodrigo de Cota en su Diálogo del amor y un viejo que nunca se había entendido y, por tanto, cuantas explicaciones se habían dado eran totalmente inútiles. Los versos dicen así:

Yo mostré retir en plata

la vaquilla y alacrán,

y hazer el solimán

qu' en el fuego se desata.

Pues bien, la vaquilla no es ni una planta silvestre, ni la grasa de vaca, sino la 'salamandra', cuyas propiedades eróticas y cuya simbología amorosa cuenta con la más gloriosa de las tradiciones. Resulta que al transcribir por los pueblos santanderinos, mi colaborador encontró vaquigüela, vacarizo, vicaruela como 'salamandra' y bien lejos de aquí, al explicar literatura medieval en la Universidad de Barcelona, las cosas se aclararon por esa terca persistencia. ¿Y ha de ser únicamente este el caso singularísimo en 'que viva aún lo que era trivial en el siglo $\mathrm{xv}$ ?

Hace ya muchos años, Karl Jaberg dijo que era totalmente absurdo oponer diccionarios y atlas lingüfsticos ${ }^{2}$ y el absurdo sigue siendo vigente. Hace poco tiempo Iorgu Iordan, retomando una interrogante de Leo Spitzer, planteaba la pregunta Atlas ou Glossaires? ${ }^{3}$. Mi postura viene a ser la de Puşcariu: atlas y diccionarios. Pero entendámonos: lo que se discute no es un atlas y un diccionario hecho por linguiistas del prestigio del propio Puşcariu ${ }^{4}$ por la orientación que un linguiista como Jaberg pudo dar al Glossaire de la Suiza románica ${ }^{5}$ y al $A I S$, sino a un cotejo que suele ser heterogéneo, y ahí está mi discrepancia con los grandes maestros. Lo que comparamos, al menos lo que en España puede

1 La "vaquilla", el "soliman" y otras cuestiones del "Dialogo entre el amor y un viejon, de Rodrigo de Cota ("Revista de Filologia Española», LVIII, 1976, pp. 6979).

2. Der rumänische Sprachatlas und die Struktur des dacorumänischen Sprachgebiets ("Vox Romanica», V, r940, pp. 66-67).

- Actas del V Congreso Internacional de Estudios Mediterráneos». Madrid, 1977, pp. 475-479.

- Bien es verdad que su participación en el atlas rumano dejó mucho que desear, cf. SEVER POP, L'Atlas Linguistique Roumain ("Revista Portuguesa de Filologian, I, 1947, p. 47 nota).

- Dirigió la obra de 1942 a 1948. 
compararse, es un diccionario hecho por beneméritos aficionados ${ }^{1}$ que carecen de formación lingüística: sus resultados son o paupérrimos ${ }^{2}$, según puede verse en la propia provincia de Santander, o de indiscriminada acumulación ${ }^{3}$; frente a esto, el atlas tiene la abrumadora ventaja de su carácter cientifico y un cotejo, como el que he hecho, no deja lugar a dudas. Yo creo que un atlas nunca agotará las posibilidades de un diccionario si se hace con el rigor con que se formularon, pongo por caso, los tres Glosarios románicos de Suiza, pero una obra así es inacabable, carece de las condiciones de un atlas (no lo olvidemos, es un diccionario) y necesitó, incluso en Suiza, de unos Tableaux phonétiques. Hay, pues, que situar atlas y diccionario en un mismo plano técnico, para no comparar cosas que por su heterogeneidad son incomparables y no olvidemos - aunque también en esto postulo mis reservas al trabajo de Iordan - que los atlas regionales han venido a ser como un puente tendido entre la lexicografia inacabable y los grandes atlas que por utilizar una red muy clara y un cuestionario general dejan enormes parcelas fuera de su estudio. $Y$ queda aparte el problema de 1a estructura del léxico, punto menos que imposible de ver con los diccionarios actuales y tan fructifera desde la consideración de los mapas lingilísticos $\bullet$.

\section{Actitudes lingüisticas}

Mucho de lo que hasta ahora he considerado son las actitudes del inventigador ante el objeto de su trabajo. Creo que las cosas quedan bastante claras aunque se hayan dicho de otro modo y para otras latitudes. La praxis exige siempre una actitud tebrica y sin teorla no hay forma de realizar ciencia objetiva. Pero solemos olvidar, y ahora, y por muchos, tanto como en los peores momentos de la lingülstica, que el

1 La situación se da en otros sitios, como bien señala Purrere Bonnaud, Cieugraphie linguistique, linguistique glographique, glographie: l'exemple de l'Auvergne («Revue d'Auvergnes, LXXXVII, 1973, p. 302, por citar un testimonio.

- Cf. Atlas lingüistico de Andalucta. Cuestionario. Granada, 1952, p. V.

- Cuestionario citado en la nota anterior, p. VI, nota 33.

- Cf. Die geographische Untersuchung von Wortfeldern en la obra de JAN GoossEns, Strukturelle Sprachgeographie. Heidelberg, 1969, pp. 70-76. Para el españd, Gricorio SAIVADOR, Estudio del campo semdntico maran en Andalucia

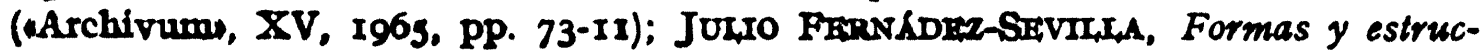
turas on el lexico agricola andaluz. Madrid, 1975; JOst ANDRts DE MOInNA, Cambios semdinticos en andaluz (tesis doctoral). 


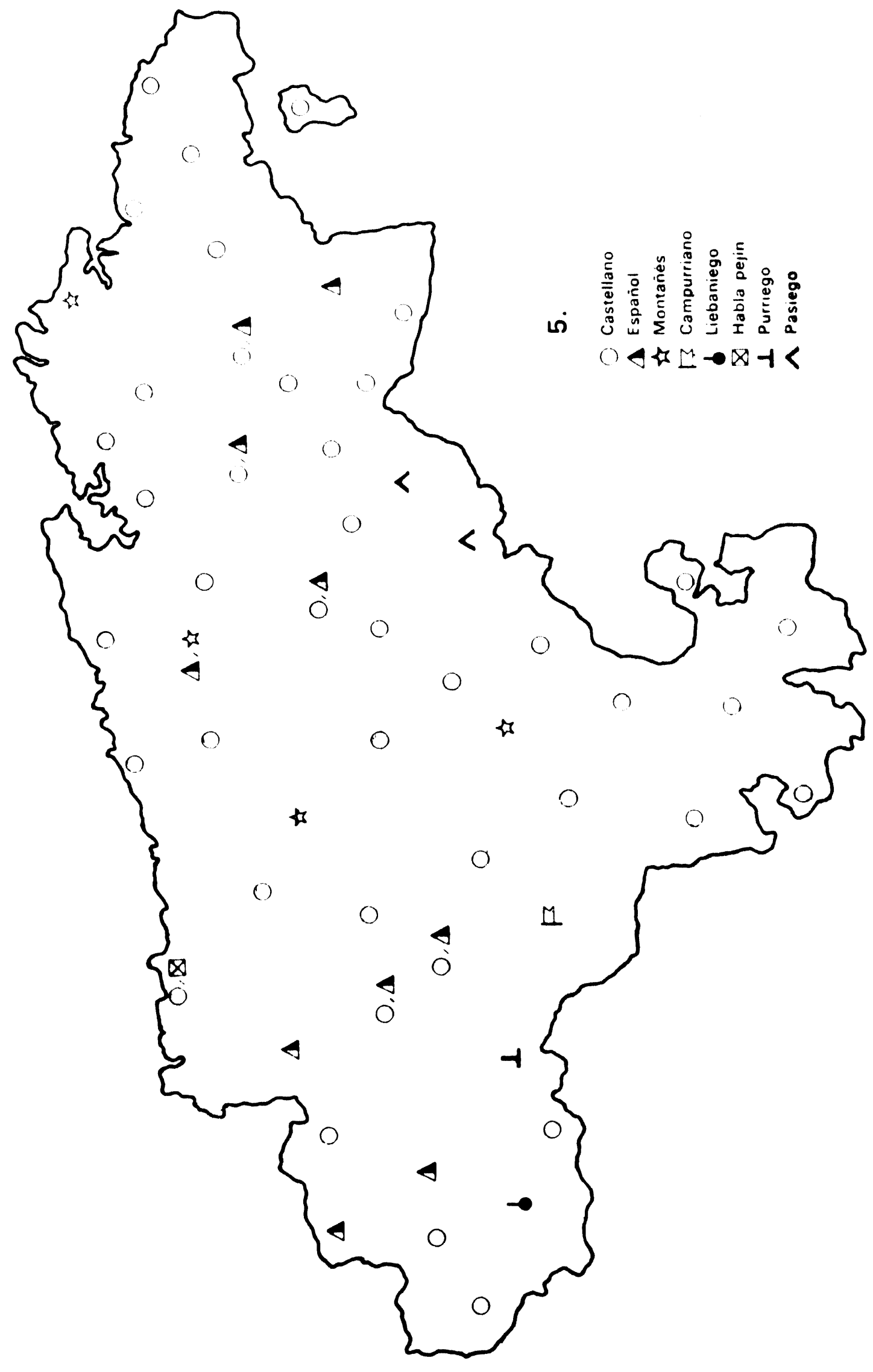


objeto de nuestro estudio sólo es posible porque hay hombres que 1o utilizan, que están conformados por él y que lo conforman. De ahí -y tampoco es nuevo- una lengua será lo que de ella hagan sus propios hablantes. $Y$ ahora mi interrogación es ésta: ¿cómo reaccionan los informadores cuando se les preguntan qué hablan? ${ }^{1}$. Hace algún tiempo publiqué un trabajo en el que catalanes, andaluces y canarios se enfrentaban con la denominación de su instrumento lingüístico, con unos resultados que no vacilo en calificar de extraordinarios ${ }^{2}$. Dicho sea en honor de gentes que sabían mucho más de su lengua - y eran analfabetos- que ciertos padres que le van saliendo por nuestras calendas. El mapa núm. 4 del $A L P I$ podría ser un espejo espléndido de realidades, sin embargo está muy mal hecho y tenemos que conformarnos con lo poco que nos da. Según él, en la provincia de Santander se habla pasiego (puntos 407, 4II), montañés (40I, 405), habla lebaniega (400) y tudanco (406). Es todo. Pero el atlas regional nos dice mucho, muchísimo más. En la conciencia de todos estos hablantes lo que actúa es la realidad de la región a la que pertenecen y que por tanto da nombre a su lengua: en Santander se habla castellano, según dijeron los informantes de cuarenta puntos, y aun ese castellano era legitimo, como dijo el sujeto de Liencres (202), limpio, según el de Fresno (500), o, con cierta restricción localista, castellano con la $u$ en Oreña (IOo) y La Hermida (I07). Castellano es, pues, la conciencia lingüística arraigada, pues no puede ser de otro modo en una provincia de Castilla, ahora bien, es, además, el ideal lingüístico que encierra en sí la perfección a la que puede aspirarse; por eso unos hablantes atemperan la afirmación con algunas restricciones atenuativas (con la $u$ ) o, según el informante de Guriezo, «aunque no se sabe hablar», el de Carmona que lo considera rebujao, los de Tudanca y San Sebastián de Garabandal, que lo estiman mal hablado. Español es denominación más escasa y su presencia habrá que juzgarla como perteneciente a supraestructuras nacionales (escuela, administración, etc.) o, lo que resulta ejemplar, a considerar español como "un supersistema en el que se integran las realizaciones dialectales», según dije, y me confirma el informante de Celis, que habla español "porque no es castellano legitimo"; con lo que venía a coincidir con aquel otro interlocutor de la isla de La Palma que, dándome la misma res-

1 A este respecto son útiles las Noterelle di sociolinguistica, de G. B. PELLIEGRINI ("Studi Linguistici Salentini, 2. Scritti in onore di V. Pisani). Lecce, 1969, pp. 99-109).

- Actitud del hablante y sociolingüistica, en Teoria lingüistica de las regiones. Madrid, 1975, pp. 91-114. 
puesta apostillaba "porque castellano no lo sabemos hablar" ${ }^{1}$. Que en regiones naturales muy diferenciadas apliquen a su variedad lingüística el nombre de la comarca, no tiene nada de particular, ni aquí ni en Canarias o Andalucía; lebaniego, campurriano, pasiego son otras tantas designaciones de carácter localista en las que se proyecta una visión de la lengua como instrumento de escaso alcance (para hablar con las gentes del valle, y nada más, pues del valle no se sale). Los hablantes de Santander al dar unos informes singularmente luminosos han venido a coincidir con otros de las más remotas geografias de España, aunque en cada sitio la fidelidad a la tierra impone su propia coherencia. Santander es Castilla y habla castellano, pero castellano se siente como un ideal lingüfstico en el que no caben desviaciones del sistema; por eso, quien tiene seguridad en el instrumento que maneja ponderará enfáticamente (castellano legitimo o castellano limpio) y, por el contrario, quien conoce la limitación de sus sistema frente al común apostillará castellano con la $u$ o dirá "aunque no se sabe hablar". Sin embargo, español es el término que se identifica con la idea de España y del mismo modo que en el concepto nacional se integran las limitaciones regionales, en la designación lingüística se integran todas las variedades discrepantes, pues español es un suprasistema que abarca a las modalidades que se apartan de ese ideal castellano, cuando al castellano "no lo sabemos hablar".

Sobre isoglosas y otras cuestiones

Creo que un atlas como el de Santander queda justificado por lo que es frente a otro tipo de inventarios. Y si se justifica frente es porque, en sí mismo, está suficientemente caracterizado. De esto quisiera hablar brevemente. He tomado media docena de mapas de campos ideológicos muy variados y en ellos vemos la heterogeneidad de la provincia. La heterogeneidad afecta a aspectos fonéticos, como el de la alternancia $b$ - / $z$ - en zarza y su derivados: se ve sin ningún género de duda que la presencia de la $b$ - es un rasgo que viene del occidente y, en efecto, está bien documentada en asturiano; por el contrario, hay áreas léxicas que oponen el norte al sur de la provincia (ejemplos calcetín de lana, artesa pequeña, becerro), otras que hacen ver cómo los términos más arcaicos quedan marginados en las zonas periféricas y

1 Teoria de las regiones, p. 99. 


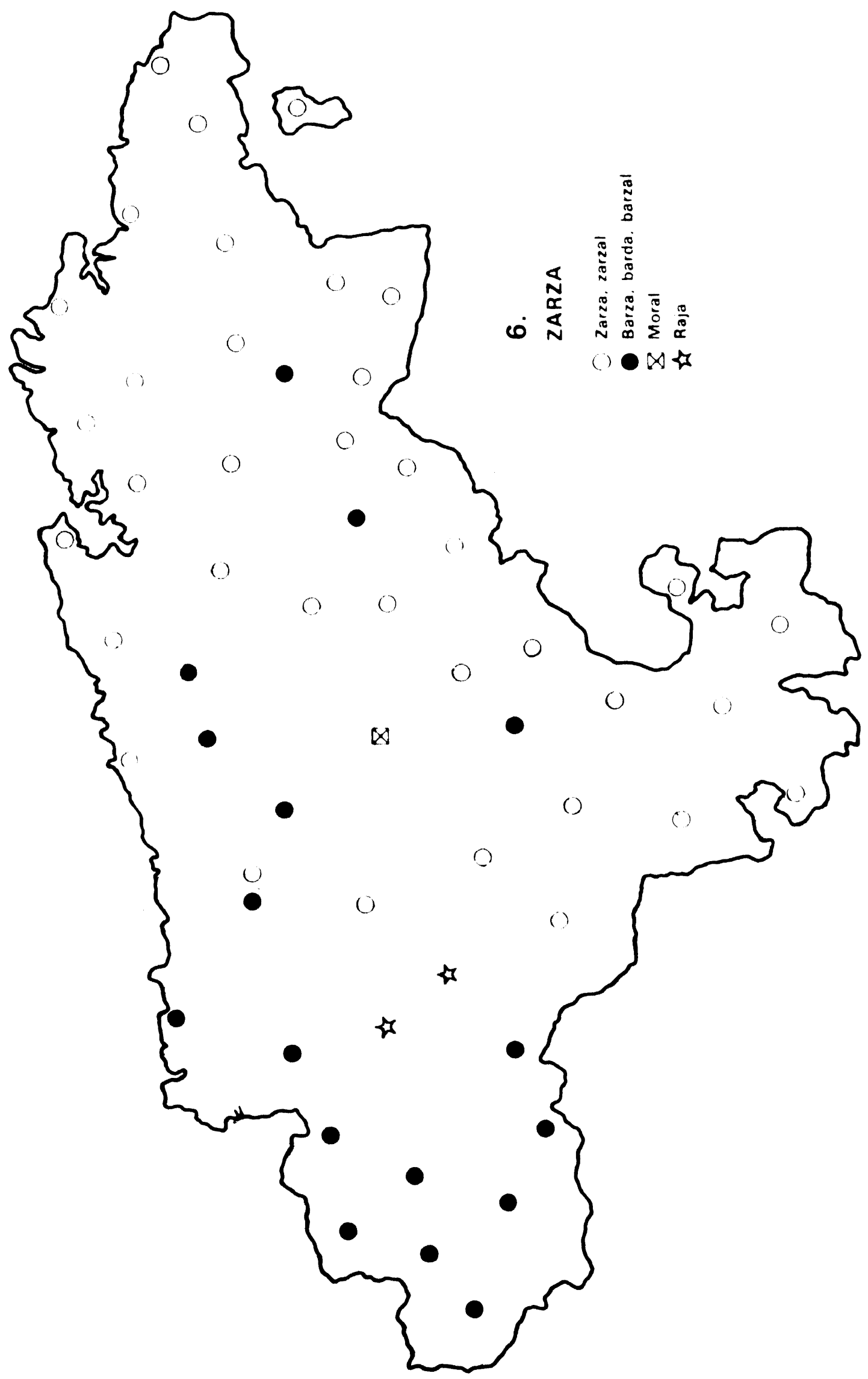




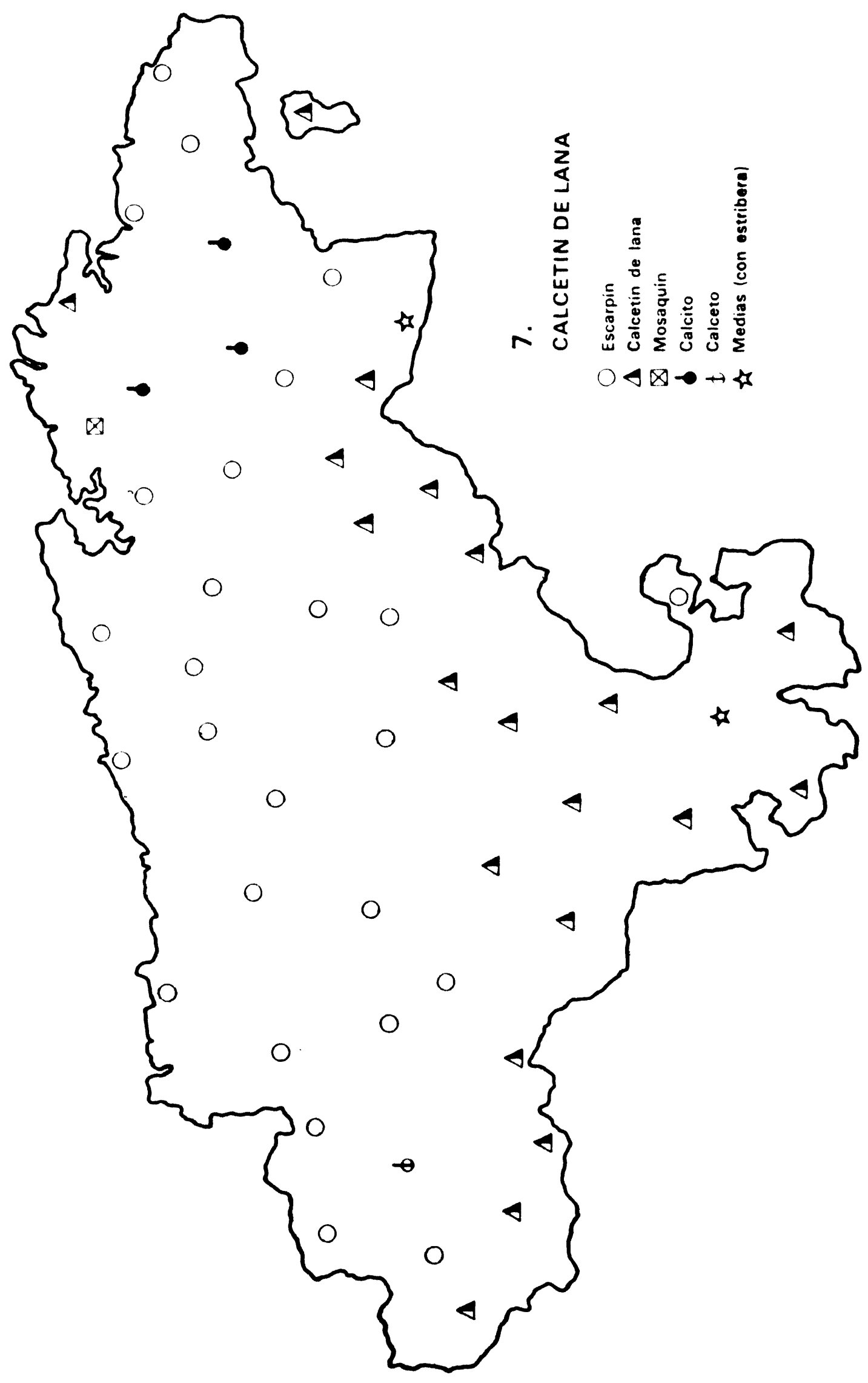




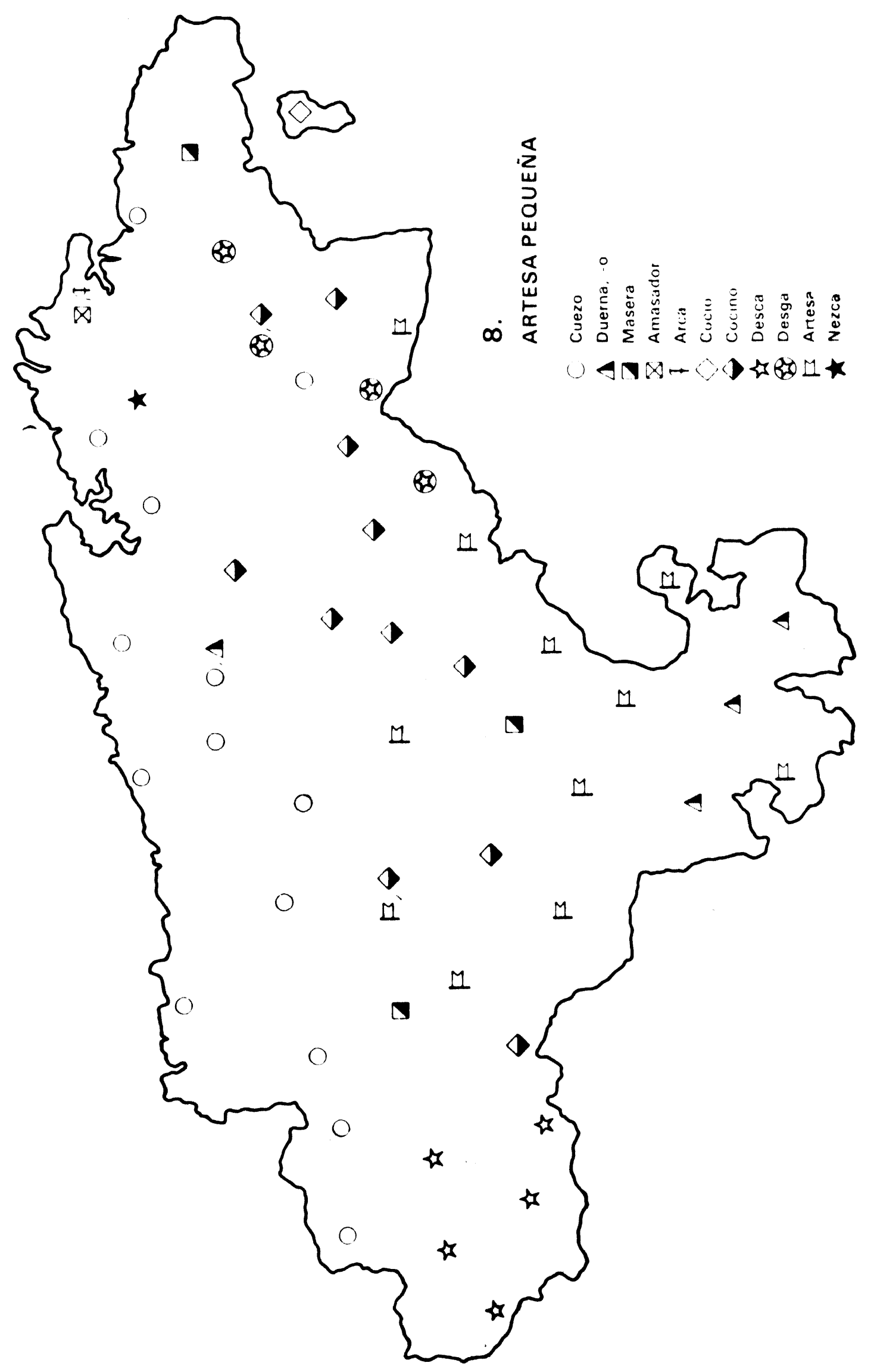


RFE, LIX; 1977 EL ATLAS LINGÜÍSTICO Y ETNOGRÁFICO DE SANTANDER

109

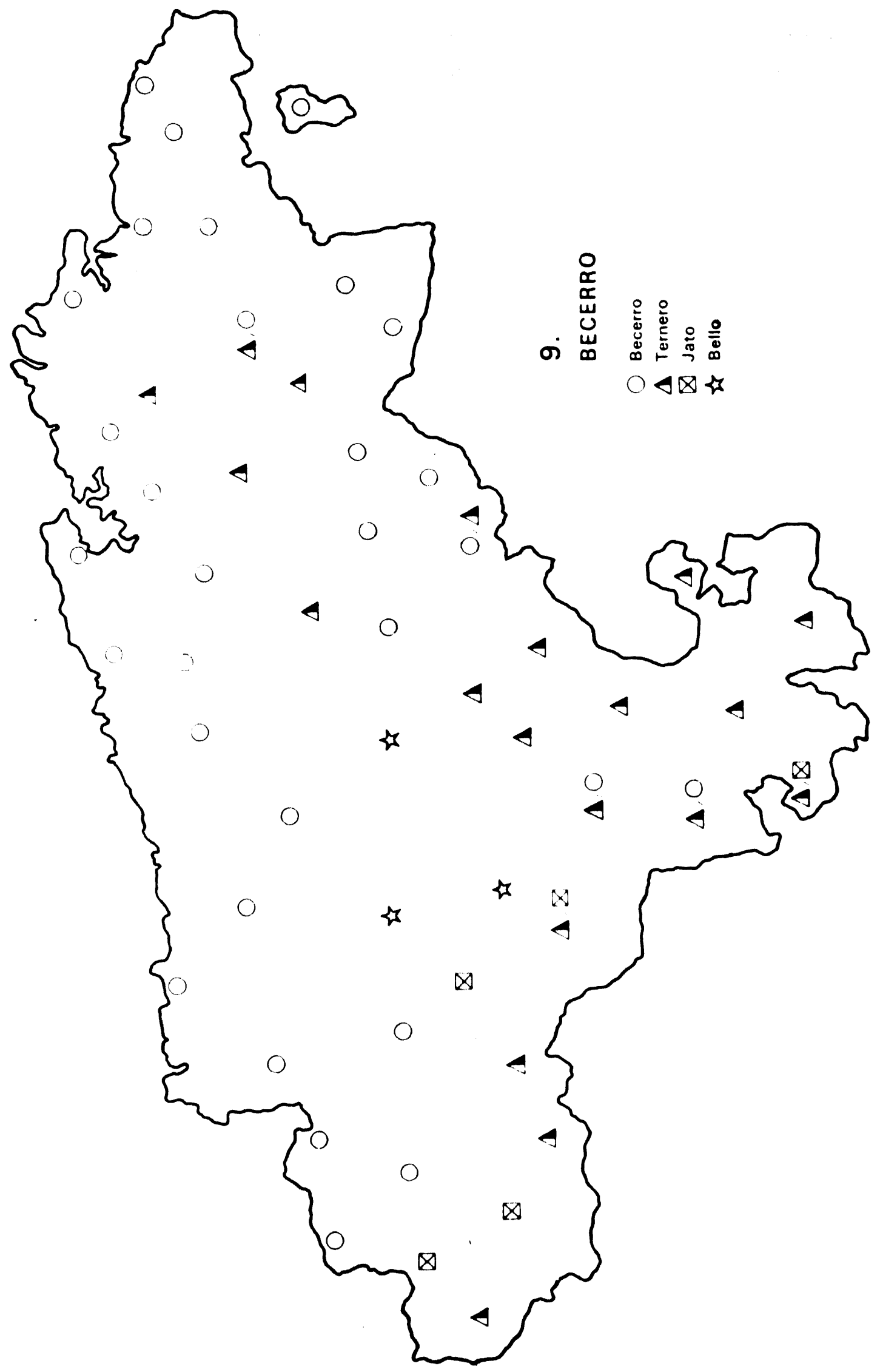

(c) Consejo Superior de Investigaciones Cientificas

http://revistadefilologiaespañola.revistas.csic.es

Licencia Creative Commons 3.0 España (by-nc) 


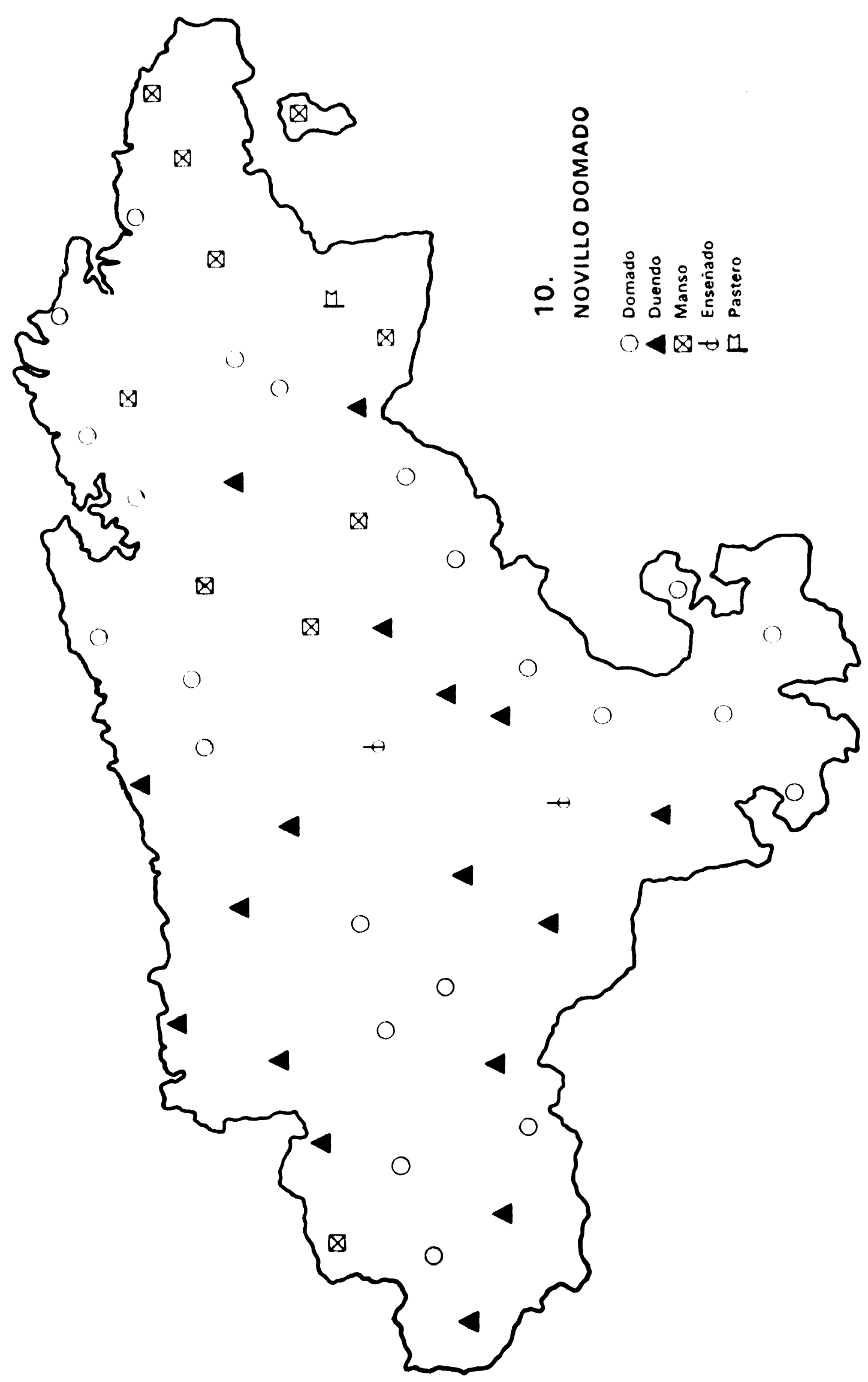




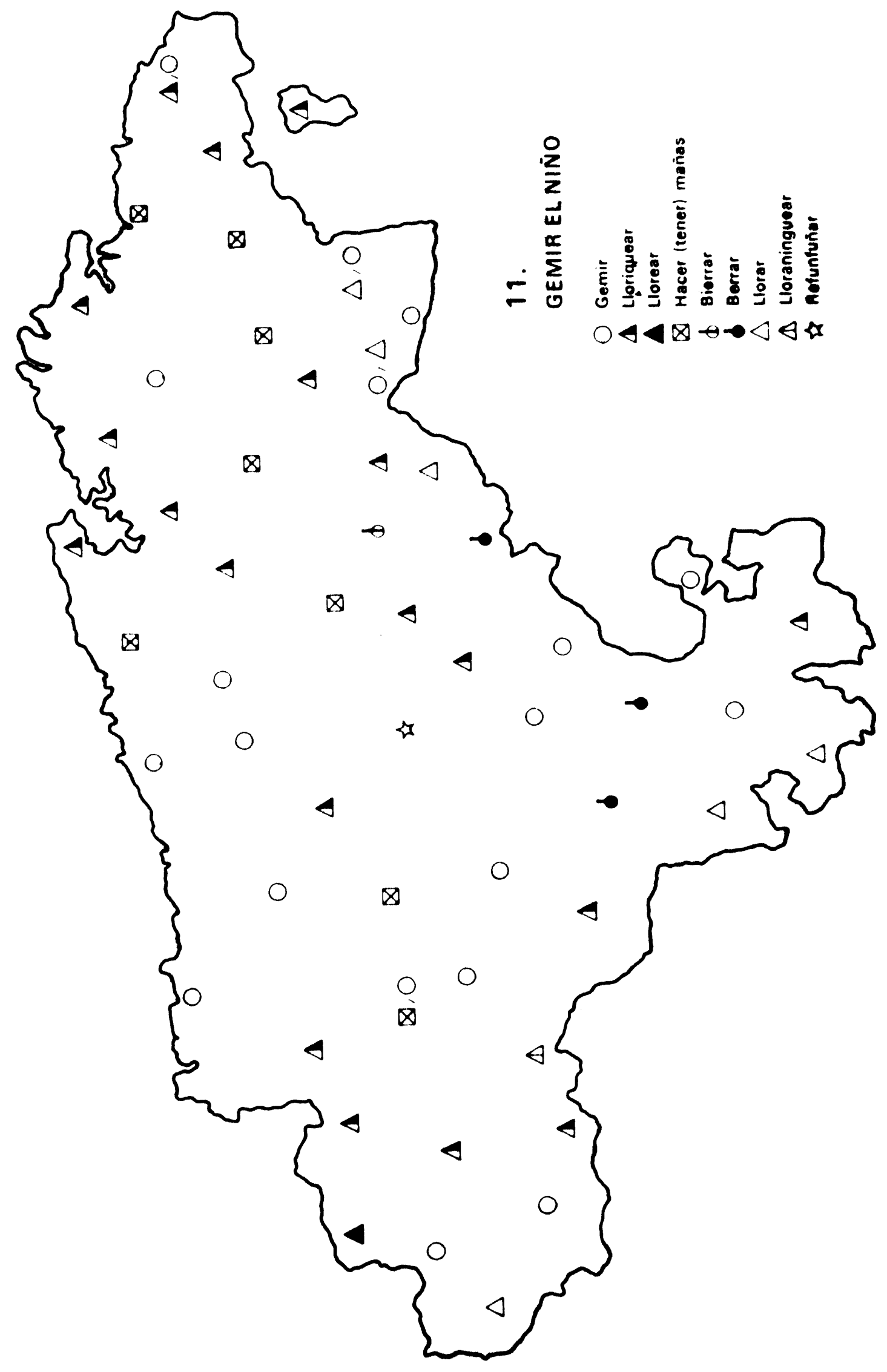


aisladas de la provincia (medias en el mapa de calcetín de lana; jato, en el de becerro), otras que manifiestan la penetración del léxico desde dominios externos a Santander (manso por 'novillo domado', jato por 'becerro'), alguna, tal vez, nos ayude a resolver el problema del origen de los pasiegos, pues vienen a unir la región de los Picos de Europa con el Valle de Pas (desca/desga como 'artesa pequeña') ${ }^{1}$. He aquí unas muestras, poquísimas muestras, entresacadas -insisto - muy al azar; sin embargo, en ellas está justificado ese principio sobre el que descansa la geografía lingüística: la diversidad. $\mathrm{Y}$ diversidad hay en una provincia a la que llegan rasgos que por oriente tienen que ver con el vasco; con el sureste con las modalidades más viejas del castellano; por el suroeste, con rasgos leoneses; con el occidente, con el asturiano. $Y$ no se trata de un sincretismo que haya presidido a cualquiera de las peculiaridades consideradas, sino que ahí está, también, la distribución nada caótica de tales rasgos y en esas áreas conexas hay una llamada a la geografía y a la historia para que expliquen el porqué de las sincronias de hoy.

Cierto que se podrá objetar que el ámbito escogido queda como un muñón muchas veces inútil si no poseemos esos elementos de comparación de los que hablaba Jaberg, y a los que he aludido al principio de estas páginas. Pero la provincia de Santander considerada ahora como una pieza autónoma, está inserta en otras empresas que le darán su cabal sentido: cuatro puertos suyos (Castro Urdiales, Laredo, Santander y San Vicente de la Barquera) están incluidos también en el atlas de los marineros peninsulares ${ }^{2}$, tres figuran en el Atlas Lingüistico de Europa ${ }^{8}$ y diecisiete en el Atlas Lingüistico de España y Portugal, terminado en los dominios del castellano y sus dialectos".

A lo largo de estas páginas he querido justificar un proyecto que hemos llevado a cabo y que en estos momentos sólo necesita la impresión. En 1976, la Excma. Diputación de Santander decidió poner en marcha una idea a la que querfa dar vida la naciente Universidad mon-

1 Vid. MANUEL DE TKRAN, Vaqueros y cabañas en los montes de Pas ("Estudias geográficos», VIII, 1947); MENÉNDEz PIDAL, Pasiegos y vaqueiros. Dos cuestiones de geografia lingüistica ("Archivum", IV, I954); GARCfA LOMAS, Los pasiegos. Estudio etnografico e historico. Santander, 1960.

2 Se entregó terminado a la Fundación Juan March en junio de 1976. De momento, vid. Atlas lingüistico de los marineros peninsulares. Cuestionario. Madrid, 1974 .

8 Cf. A. WeIJNEN, Atlas Linguarum Europae. Introducción (trad. Manuel y Carlos Alvar Ezquerra). Madrid, 1976.

- El Cuestionario se imprimió en Madrid, 1974. 
tañesa. Mi maestro el Prof. Ynduráin se encargó de solucionar las dificultades de la colaboración y un santanderino de pro, don Ignacio Aguilera, fue generoso de su saber y su tiempo hasta límites que rompen la palabra gratitud. Ellos y la Diputación Provincial hicieron posible la obra. Nosotros trabajamos: redacté un cuestionario larguísimo (con más de tres mil cuestiones), lo probamos en varios pueblos en el verano de 1976 y en septiembre de ese año comenzaron las encuestas. Todo esto requiere, también, alguna aclaración.

El cuestionario ha sido muy extenso y bastante original ${ }^{1}$. Pienso en la fisonomía de la región, su fuerte personalidad y una geografia que condiciona desde la economía hasta las viviendas. Por eso iban a serme muy poco útiles los cuestionarios que me sirvieron para realizar mis atlas de Andalucia, de Canarias, de Aragón, Navarra y Rioja, y, por supuesto, el de España y Portugal. Si tuviera que aclarar estos hechos dentro de la tradición románica, dirfa que mi situación en Santander podía parecerse algo, sólo algo, a la de Nauton para preparar su cuestionario para el Macizo Central: el malogrado dialectólogo francés estaba en una zona pequeña, uniforme lingülsticamente, pero muy fuertemente caracterizada; resolvió sus dudas componiendo-dentro de la tradición de Gardette - un cuestionario muy extenso, que debería ser preguntado en pocos puntos ${ }^{3}$. Yo estaba ante una pequeña región, si, pero muy heterogénea, tremendamente erosionada en sus contenidos tradicionales, virtualmente desconocida. Creo que debia dar a mis problemas una solución semejante: inventariar todo lo anterior para saber su validez actual, ampliar las preguntas para no perder nada $\mathrm{y}$ adensar la red de investigación tanto como me fuera posible para hacer una obra que pueda durar más que el bronce. $Y$ recurri a un cuestionario muy rico. Los resultados han ido reflejándose en las pobres muestras que he traido a estas páginas.

Pero buscar la personalidad de la región no es desmigajar la unidad existente. Desde los comienzos del Atlas Lingüistico de Francia, por regiones, se buscó la coherencia de cada parte con el todo para saber no sólo la realidad de cada dominio, sino la situación del francés en

1 Para los caracteres de un cuestionario nacional y otro regional, vid. JABERG, Grossräumige, pp. 50-52.

2 Cf. Estructuralismo, geografía lingüistica, ya citado, p. 136, nota 9.

- Problemas de los que aquil trato se pueden encontrar en varios de los trabajos que se incluyen en el Colloque de Dialectologie, publicado por P. Imas y G. STRAKA. Estrasburgo, 1957. 
ese medio siglo transcurrido desde Gilliéron a Dauzat '; que no siempre se consiguiera ya es otra cuestión ${ }^{2}$. En el sentido de que hubiera uua parte común en todos los cuestionarios, se han pronunciado propios y extraños, para que no puedan valer aquellas palabras de Jaberg en las que hablaba de la insolidaridad del $A L F$ con los otros de que se disponía en $1954^{3}$. Como en otra parte he escrito palabras que ahora me justifican, me ahorraré más amplio comentario: "Conviene, pues, con objeto de poder establecer ulteriores conexiones, cada director de un nuevo atlas regional de cabida en su cuestionario a un nutrido número de preguntas de las que figuran en los precedentest ${ }^{4}$. Las referencias que en mis mapas hago al resto de los atlas románicos sirven de ayuda para establecer estas relaciones.

En efecto, el Atlas de Santander tiene su cuestionario propio; con él he querido agotar, en la medida de lo que humanamente es posible y el propio método permite, lo que aún caracteriza a la provincia, pero Santander no es un castillo que Aladino saca del fondón de los mares; es una pequeña realidad inserta en otra inmensamente mayor ${ }^{5}$. Para saber cómo se engarza esta lingüística microcósmica en la mactocósmica he mantenido un número no escaso de cuestiones que figuran en los otros atlas regionales de España e incluso en el plurilingüe de Europa. De este modo salvo la coherencia que defendí en el Congreso de Bucarest, y que sigo considerando básica para el bien de nuestros estudios ${ }^{6}$.

Las encuestas las hice con dos abnegados colaboradores, antiguos alumnos míos y, ya, doctores en Lingüistica Hispánica: José Antonio Mayoral y Carlos Alvar. Les debo una gratitud que va más allá de de mis palabras: ellos lo saben, y para mí es suficiente. Los tres somos profesores universitarios (en Madrid, en Barcelona) y nuestro tiempo libre lo dedicamos a esta empresa: en cada campaña de encuestas, hać́amos más de 3.000 kilómetros por las carreteras de la provincia para aplicar a nuestro trabajo la decantada investigación en zig-zag, que tantos beneficios reporta, aunque nuestras fuerzas padecieran. Carlos Alvar que hizo de chófer fue nuestro ángel de la guarda en los casi

1 Vid. la información de Estructuralismo, geografía lingüistica, p. I 2.

ibidem, pp. 135-138.

- Grossräumige, p. 56.

- Estructuralismo, etc., p. 139.

- De acuerdo, por ejemplo, con JABERG, Grossräumige, p. 59.

- A una situación semejante tuvo que enfrentarse G. Contossopouros en su $O$ glossikos atlas tes Kretes. Atenas, 1975. 
12.000 kilómetros recorridos. Normalmente, fui yo el fotógrafo de la expedición, y obtuvimos más de dos mil fotografías etnográficas, que tenemos clasificadas por el triple sistema de ordenación que apliqué a todos mis atlas.

Tras mucho cavilar y hacer algunas pruebas, decidí el trabajo en las localidades que estábamos visitando. En cada pueblo no podíamos demorarnos tres o cuatro días porque no encontramos ni un solo lugar donde la gente quisiera comprometerse tanto tiempo ${ }^{1}$. Entonces, en vez de trabajar cada uno en un pueblo distinto, según hice con mis colaboradores en Andalucía o Aragón, Navarra y Rioja, en Santander encuestábamos juntos y nos tepartíamos las preguntas entre los tres. Tampoco este criterio fue tomado a humo de pajas: intentamos preguntar indiscriminadamente, pero, aunque para el explorador sea peor limitarse a un aspecto del conjunto, resulta mejor por otra parte por cuanto asegura certeza para identificar las respuestas y uniformidad en las transcripciones que puede tener en cuenta quien considera la obra ${ }^{2}$. Así, pues, la uniformidad de criterio queda bien respetada: el mismo explorador preguntó de manera constante fonética, morfología, sintaxis y parte del léxico, con lo que siempre estarán esos rasgos fonéticos como muestra segura del habla. Independientemente de que al cartografiar nos decidamos a presentar el léxico - sólo el léxico- en mapas elaborados. Yo respondo de las preguntas I-I.300, Carlos Alvar de las I.3OI-

1 Las preguntas se formulan de modo indirecto, única forma que considero válida en estos trabajos; la traducción lengua nacional-dialecto, me parece que da unos resultados totalmente falsos; el explorador debe saber muy bien qué es lo que se responde para no caer en malas interpretaciones, cf. JABT:RG, Der runünische Sprachatlas und die Struktur des dacorumänische Sprachgebiets ("Vox Romanican, V, I940, p. 55). Claro está que la sintaxis plantea otras cuestiones, lo que hizo que ante sus dificultades sólo se incluyera un número limitado de cuestiones sintácticas en el $A L R$ de Puşcariu o en mi ALEICan, mientras que la especial situación de otros dominios me obligó a un riquísimo muestrario sintáctico ( $A L E A N T$ R, $A L I: P$ ). Creo que Leo Spitzer no tuvo en cuenta el modo de formular las preguntas cuando rechazaba, en un trabajo polémico sin razones suficientes, los presupuestos de Gilliéron (Atlas linguistiques ou grammairesdictionaires-textes?; en la "Revue Internationale des fitudes Basques», XIX, 1928, p. 171).

2 Los informantes estaban condicionados por la naturaleza del cuestionario. Como siempre, nuestra elección de las personas nativas se hace con el máximo rigor y de acuerdo con las exigencias que considero fundamentales; por eso no utilizo gentes de elevada cultura (como Edmont, o Haust en su Atlas de Valonia), sino hombres que poseen aquello que buscamos: campesinos, pastores, artesanos. Vid. mi Estrucluralismo, ya citado (pp. 153-155); no de otro modo se expresó Jaberg a propósito del rumano (Der vumänische Sprachatlas, p. 51). 
2.000 y José Antonio Mayoral desde ésta al final del cuestionario. Durante el curso académico redactábamos los mapas y ordenábamos el material etnográfico ${ }^{1}$. De este modo, en menos de dos años hemos realizado todas las tareas, desde preparar el cuestionario y transcribir unas 150.000 voces hasta dar forma definitiva a los mapas.

Las encuestas se han cumplido en 55 lugares de la provincia, elegidos - como en mis otros atlas españoles - según la división en partidos judiciales. Para los amigos de la estadística, diré que la provincia de Santander tiene $5.289 \mathrm{Km}^{2}$ y 467.138 habitantes; lo que da un punto para cada $96,18 \mathrm{Km}^{2}$ y 8.494 habitantes, densidad superior a cuantas conocemos, pues en Cataluña se exploró un punto por cada $600 \mathrm{Km}^{2}$ y 50.000 habitantes; en Andalucía, uno por $379 \mathrm{Km}^{2}$ y 24.334 habitantes; en Canarias, $142,4 \mathrm{Km}^{2}$ y 22.946 habitantes; en Aragón, $432 \mathrm{Km}^{2}$ y 9.945 habitantes; en Navarra, $289 \mathrm{Km}^{2}$ y 12.900 habitantes; en Rioja, $239 \mathrm{Km}^{2}$ y $\mathrm{II} .228$ habitantes, respectivamente ${ }^{2}$.

Los puntos escogidos y el número que les asignamos en la cartografía son:

\begin{tabular}{|c|c|c|c|}
\hline S Ioo & Oreña & S 203 & Castanedo \\
\hline $\mathbf{S}$ IOI & San Vicente de la Bar- & S 204 & Laredo \\
\hline & quera & S 205 & Orejo \\
\hline S 102 & Torrelavega (Juncos) & S 206 & Hazas de Cesto \\
\hline S I03 & Helguera & S 207 & Castro Urdiales \\
\hline S I04 & Udías & S 208 & Villaescusa \\
\hline S 105 & Celis & S 209 & Ampuero (La Aparecida) \\
\hline S I06 & Herrera de Ibío & S 210 & Guriezo \\
\hline S I07 & Hermida & $S 2 I I$ & Riotuerto \\
\hline S 108 & Tresviso & $\mathrm{S} 2 \mathrm{I} 2$ & San Miguel de Aras \\
\hline S 200 & Santander & S 213 & Matienzo \\
\hline S 20I & Noja & $\mathrm{S} 2 \mathrm{I}_{4}$ & Penilla \\
\hline S 202 & Mortera de Piélagos & S 300 & Cabuérniga \\
\hline
\end{tabular}

1 No puedo ocuparme aquí de los problemas etnográficos del atlas, por más que tienen en él una parte importantísima. Desde el $A I S$ se viene incluyendo la cultura popular en nuestros quehaceres, y creo haberme preocupado mucho por la cuestión (cf. Julio Caro Baroja en su reseña del $A L E A$, "Revista de Dialectologia y Tradiciones Populares", XXI, 1965, pp. 429-438). De la necesidad de estos trabajos conjuntos habló hace muchisimos años E. TAPPOLET, Bedeutung der Sprachgeographie (*Aus romanischen Sprachen und Literaturen. Festschrift Heinrich Morf», Halle, I905, pp. 387-389, especialmente).

- Datos tomados de España. Amuario Estadistico, 1977. Año LIII. 


\begin{tabular}{|c|c|c|c|}
\hline S 301 & Villanueva & S 402 & Villacarriedo \\
\hline S 302 & $\begin{array}{l}\text { San Sebastián de Gara- } \\
\text { bandal }\end{array}$ & $\begin{array}{ll}\text { S } & 403 \\
\text { S } 404\end{array}$ & $\begin{array}{l}\text { Ramales de la Victoria } \\
\text { San Vicente de Toranzo }\end{array}$ \\
\hline S 303 & Potes & S 405 & Arredondo \\
\hline 304 & Camaleño & S 406 & Vega de Pas \\
\hline 305 & Tudanca & S 407 & Veguilla \\
\hline 306 & Bárcena Mayor & S 408 & San Pedro del Romeral \\
\hline 307 & Molledo & S 409 & La Población de Yuso \\
\hline 308 & Fspinama & S 500 & Reinosa (Fresno) \\
\hline 309 & La Vega de Liébana & S 501 & Villanueva \\
\hline S 310 & Pesquera & S 502 & Olea \\
\hline S 3 II & Salcedo & S 503 & Aldea de Ebro \\
\hline $\mathrm{S} 3 \mathrm{I} 2$ & Pesaguero & S 504 & San Andrés de Valdelo- \\
\hline 3 & Abiada & & $\operatorname{mar}$ \\
\hline 400 & La Cárcova & S 600 & Villaescusa \\
\hline 401 & Villaverde de Trucios & S 601 & Polientes (Valderredible) \\
\hline
\end{tabular}

La numeración se ha asignado - como en todos mis atlas- con la sigla que la provincia tiene en las referencias del Ministerio de Obras Públicas (S) y un número que procede de la división de la provincia en seis ámbitos: dos verticales (oriente y occidente) y tres horizontales (norte, centro y sur), de acuerdo con el siguiente esquema:

\begin{tabular}{|c|c|}
\hline 100 & 200 \\
\hline 300 & 400 \\
\hline 500 & 600 \\
\hline
\end{tabular}

\section{Conclusión}

Cualquier trabajo cientifico, si lo es, queda justificado en sí mismo. Pero siempre asalta la duda de que nuestra cultura practique un estéril bizantinismo. Lo que he explicado en estas páginas es -creo- la justificación de un quehacer que nos lleva al conocimiento de una parcela de nuestra lengua sobre la que aún pesa la losa de la ignorancia. Pero saber es algo más que una curiosidad respetable, pero intrascendente; es dar sentido dentro de lo que llamamos especular a lo que 
pudiera quedarse en unos informes de menuda erudición. El atlas de la provincia de Santander nos da - sí- unos datos inmediatos sin los cuales no podríamos elaborar nunca ni la más modesta de las teorías que necesitara de ellos, pero plantea un conjunto de problemas que pertenecen al conocimiento de una de las grandes lenguas de cultura y permite - también - acceder a los hechos generales. Y esto quisiera haber mostrado: cierre y metafonía vocálicas son más que hechos montañeses por más que en la Montaña se produzcan ${ }^{1}$, aspiración de la $s$ implosiva es - ni más ni menos- un aspecto del milenario proceso de la «demolición" de la $s$ indoeuropea ${ }^{2}$, aspirada o velar son resultados de hechos de fonética general de enorme trascendencia en el propio mundo hispánico $^{3}$, neutralización o distinción de $l l / y$ son fenómenos que se dan en mil lenguas y que en la nuestra libran hoy una riña en la que está en juego la reestructuración del sistema de las palatales $(c h . l l, y)^{4}$, por no citar sino unos cuantos ejemplos a los que me he tenido que referir. Esto, y la estratigrafía del léxico, es lo que hace que en los mapas de Santander asistamos a una de tantas batallas como libra la vida de la lengua, y su sentido no está en esos $5.289 \mathrm{Km}^{2}$ de nuestro estudio, sino en los millones y millones sobre los que el español se habla. Y quedan todavia otros problemas que tienen que ver con hechos de la metodologia lingüística: llamémoslos coexistencia de atlas de grandes y pequeños dominios; características, metodología y fines que a cada uno de ellos afecta; oposición de atlas frente al diccionario; la vida del lenguaje proyectada sobre hechos que justifican su existencia (la sociedad), sobre el dinamismo de su existencia (biología lingüística), sobre las relaciones con el pueblo que la habla (etnolingüística). No trato de hacer apologías sino de confirmar lo que en otras ocasiones ya ha sido dicho, pero es que todo ello lo hemos encontrado en este pequeño cosmos que he tratado de presentar $y$, en ello, va también la justificación del quehacer. Para que esa justificación no sea pura teoría, hemos llevado a cabo nuestro trabajo: convencer de su necesidad también es quehacer cientifico.

Manuel, Alvar

1 Vid. más arriba, páginas 91-93.

2 Teoria lingiilstica de las regiones, pp. 63-90.

- Al trabajo de la p. 85, nota $I$, añádase una obra de conjunto referida a la otra banda del Atlántico: CANFIKL, La pronunciación del español en América. Ensayo historico-descriptivo. Bogotá, 1962, pp. 71-72 y 73-75.

- Vid., por ejemplo, Niveles socioculturales en el habla de Las Palmas. Las Palmas de Gran Canaria, 1972, pp. I 24-128. 